\title{
Obligatory reflexivity in a Minimalist grammar of Afrikaans
}

\author{
Johan Oosthuizen \\ Department of General Linguistics, Stellenbosch University, Stellenbosch 7600, South Africa \\ E-mail: jo@sun.ac.za
}

\begin{abstract}
This paper deals with the phenomenon of obligatory reflexivity in Afrikaans. Adopting the general framework of Minimalist Syntax, an attempt is made to develop a novel analysis of this phenomenon that can provide a conceptually adequate account for the facts, and that is amenable to extension beyond Afrikaans. The basic idea underlying the proposed "nominal shell analysis (of obligatory reflexivity)" (NSA) is that two expressions which enter into an obligatory coreferential relationship - in this case, the reflexive and its antecedent - are initially merged into the same constituent. It is proposed that these two expressions form part of a nominal shell structure which is headed by an identity focus light noun $n$, a functional category which belongs to a natural class of identificational (or quantificational) elements. This $n$ represents the locus of the -self suffix that is normally found with reflexive pronouns in Afrikaans. The coreferential relationship between the reflexive and its antecedent is established in this nominal shell via phi $(\varphi)$-feature valuation, with the light noun acting as intermediary. It is claimed that the NSA can provide an empirically adequate account of the relevant facts without appealing to any theoretical devices or features that are not provided by or that are incompatible with the basic assumptions and concepts of Minimalist Syntax.
\end{abstract}

Keywords: reflexivity, coreferential relationship, Minimalist Syntax, Afrikaans grammar.

\section{Introduction}

This paper deals with the phenomenon of obligatory reflexivity in Afrikaans, that is, with constructions where a pronoun can only be interpreted as referentially dependent on some other expression in the sentence. Some examples of such constructions are given below; in each case, the pronoun hom/haar ("him"/"her") obligatorily takes its reference from the subject Jan/Marie'.

(1) Jan $\operatorname{Jat}_{\mathrm{i}}$ het hom $/ *$ hom $_{\mathrm{j}}$ verset teen die aanval.

Jan has him resist against the attack

"Jan resisted the attack"

\footnotetext{
${ }^{1}$ For a detailed description of the various reflexive constructions in Afrikaans, cf. Oosthuizen (2013:ch. 2).
} 
(2) Marie $i_{i}$ het die baba oral met haar $/$ * haar $_{j}$ saamgeneem.

Marie has the baby everywhere with her along-took

"Marie took the baby everywhere with her"

(3) Jan skyn homi $_{\mathrm{i}} / *$ hom $_{\mathrm{j}}$ goed te gedra.

Jan seems him well to behave

"Jan seems to behave himself well"

(4) Marie skaam haar $/$ * haar $_{\mathrm{j}}$ bloedrooi.

Marie shames her blood-red

"Marie is turning crimson with shame"

(5) $\quad \operatorname{Jan}_{\mathrm{i}} \mathrm{kon} \mathrm{sy}_{\mathrm{i}}$ lag / * sy lag nie hou nie.

Jan could his laugh not keep NEG

"Jan couldn't stop himself from laughing"

Limiting the discussion to those constructions in which the reflexive pronoun occurs as the object complement of a verb, as in (1), a novel minimalist analysis is proposed to account for the facts, one which seems amenable to extension beyond Afrikaans ${ }^{2}$. The basic idea underlying this analysis, which may be referred to as the "nominal shell analysis (of obligatory reflexivity)" (NSA), is that two expressions which enter into an obligatory coreferential relationship are initially merged into the same constituent. More specifically, it is argued that these two expressions form part of a nominal shell structure which is headed by an identity focus light noun $n$, a functional category which belongs to a natural class of identificational (or quantificational) elements ${ }^{3}$.

The main assumptions and devices of the NSA are introduced in the form of nine hypotheses in section 3. The question throughout is whether the NSA is (i) empirically adequate in the sense that it can account for the relevant facts of Afrikaans, and (ii) conceptually adequate in the sense that it incorporates theoretical devices which are either provided by or compatible with the basic assumptions and concepts of Minimalist Syntax. In the course of the discussion, attention is also given to the analysis of constructions in which a pronoun either cannot or may (but need not) receive a reflexive interpretation. The main findings are summarised in section 4. Before proceeding, however, a brief clarification is given in section 2 of some basic concepts concerning reflexivity and related phenomena which, although widely used, are often (partially) misunderstood.

\section{Basic concepts relating to coreferentiality}

Linguistic utterances are commonly used for talking about states of some world, whether the real or an imagined world. Referents in that world - say, objects or persons - are picked out by means of so-called "referential expressions". For instance, John, the girl, herself and him in the utterances in (6a-d) are all examples of referential expressions.

\footnotetext{
${ }^{2}$ Cf. Oosthuizen (2013) for an account of the various other reflexive constructions in Afrikaans in terms of the proposed analysis, and for the manner in which the main ideas of this analysis can be extended to other languages and to other types of constructions, e.g. floating quantifier and expletive daar ("there") constructions.

${ }^{3}$ It is argued in Oosthuizen (2013) that this class also includes a contrastive focus $n$, a presentational focus $n$, a possessor focus $n$, and a quantity focus $n$.
} 

a. John hurt the girl.
b. The girl hurt herself.
c. John says that the girl hurt him. (i.e. someone other than John)
d. John says that the girl hurt him. (i.e. John himself)

Referential expressions like those in (6) fall into two broad kinds: those that are "referentially independent" and those that are "referentially dependent". Note that the entities that are picked out by referential expressions (that is, their referents) are not independent of the mental states of the language user. This means that any referential relationships that are established through the use of linguistic expressions are internal to the language user. In short, a "referential relationship" does not exist between the expressions of language on the one hand, and a world outside of and separate from the mental states of the language user on the other'.

The relations of referential (in)dependence among certain expressions in utterances can be described by means of the following approximate generalisations: ${ }^{5}$ the first generalisation is that some referential expressions can be used independently - that is, solely by virtue of their intrinsic meaning - to pick out a referent. Both John and the girl in the utterances in (6) are examples of such an expression, generally known as a "referring (r)-expression". This means, then, that r-expressions are referentially independent.

The second generalisation entails that some referential expressions, generally known as "anaphors", cannot be used to pick out a referent solely by virtue of their own intrinsic meaning; they are referentially dependent on some other expression in the utterance. An example of an anaphor is the reflexive pronoun herself in (6b); in this utterance, herself gets its reference from the expression the girl - the latter is known as the "antecedent" of the anaphor. An anaphor is said to be "coreferential" with its antecedent. Note, however, that although the anaphor picks out the same referent as the antecedent, it does so derivatively, that is, via the antecedent. In this sense, then, the anaphor herself in (6b) enters into a (derivative) coreferential relationship with its antecedent the girl.

The third generalisation is that some referential expressions can be used like both r-expressions and anaphors. An example of these expressions, generally known as "pronominals", is the personal pronoun him in (6c,d). In (6c) him is used, just like an r-expression, to refer to someone in the world solely by virtue of its own intrinsic meaning; that is, it independently picks out a referent other than that picked out by John, itself an r-expression. In (6d), however, him is used like an anaphor: taking John as its antecedent, it derivatively picks out the same referent as that picked out by John.

The fourth generalisation entails that the establishment of a coreferential relationship between a referentially dependent expression and an antecedent is subject to several grammatical conditions. One such condition is that the referentially dependent expression must agree with its antecedent in regard to phi $(\varphi)$-features, that is, the formal grammatical features of person, number and gender. This means that (the values of) the $\varphi$-features of the antecedent must be

\footnotetext{
${ }^{4}$ Cf. Chomsky (2004) and Smith $(1998,1999)$ for a discussion of the distinction between the idea just outlined and the alternative idea that a linguistic expression by itself refers to an entity or state of affairs outside of the mental states of the language user.

5 These generalisations are loosely based on Chomsky $(1981,1995)$.
} 
exactly the same as that of the referentially dependent expression, as is the case in (6b). The utterances in (7), by contrast, do not meet this requirement, hence their unacceptability.
a. *The girl hurt myself.
b. *The girl hurt themselves.
c. *The girl hurt himself.

A second condition is that a referentially dependent expression - more specifically, an anaphor - and its antecedent must not be "too far apart"; in technical terms, they must both occur in the same "local domain" in a sense that has to be made precise. For example, in (8a) the anaphor himself and the r-expression the boy are both contained in the subordinate clause. This utterance is acceptable with himself taking the boy as its antecedent; in fact, this is the only possible interpretation of the anaphor. In (8b), by contrast, himself forms part of the subordinate clause whereas the boy serves as the subject of the main clause. In this case, himself cannot enter into a coreferential relationship with the boy, as is illustrated by the unacceptability of the utterance. In short, in (8a) the anaphor and its antecedent are "close enough" for a coreferential relationship to be established, but not in $(8 b)^{6}$.
a. John said that the boy hurt himself.
b. *The boy said that Mary hurt himself.

The fifth generalisation states that, within a given local domain, the interpretation of an anaphor differs systematically from that of a pronominal in the sense that the anaphor must take its reference from an antecedent in that domain whereas the pronominal cannot. This is illustrated in $(9)^{7}$.
a. John said that the boy hurt himself. (himself = the boy)
b. John said that the boy hurt him. (him $=$ John or some other male individual)

Any proper account of the generalisations mentioned above has to provide answers to the following questions, amongst others:

- $\quad$ By what formal means can the distinction between anaphors, pronominals and r-expressions be described?

- $\quad$ By what formal means can the establishment of a coreferential relationship between an anaphor (specifically, a reflexive) and some other expression (its antecedent) be accounted for?

The relations of referential (in)dependence among certain expressions in utterances have been a core topic of investigation in Generative Linguistics over the past fifty years, and various

\footnotetext{
${ }^{6}$ These examples serve only to illustrate the idea of a locality condition on the coreferential relationship between an anaphor and its antecedent. It is important to note that it is not necessarily a clause that counts as the relevant local domain.

${ }^{7}$ It will be shown in section 3 that Afrikaans allows constructions in which this generalisation does not hold; with verbs belonging to specific semantic classes, a pronoun can in fact receive both a reflexive and a non-reflexive interpretation in the same domain.
} 
attempts have been made to provide adequate answers to the above questions ${ }^{8}$. However, a detailed, critical discussion of the empirical and conceptual merits and shortcomings of existing generative analyses of reflexivity and related phenomena falls outside the scope of this paper. Rather, based on the facts of Afrikaans, the main objective is to make explicit the assumptions and devices of an alternative minimalist analysis of obligatory reflexivity, which forms the topic of the next section.

\section{A nominal shell analysis of obligatory reflexivity}

A basic assumption of the NSA is that the structural relationship between a reflexive pronoun and an antecedent expression is established by syntactic devices in a particular syntactic configuration. By contrast, the semantic interpretation of this relationship - specifically, interpreting the pronoun as coreferential with or referentially dependent on the antecedent - is determined by a device of the semantic component ${ }^{10}$. Focusing on the syntactic aspects, the NSA addresses the following general question: Which syntactic devices are required (i) for generating the configuration containing a reflexive pronoun and its antecedent, and (ii) for establishing the relevant structural relationship between these constituents? The question of the semantic interpretation of the structure containing the reflexive and its antecedent will, however, also be addressed briefly in the course of the discussion. The proposed analysis is "minimalist" in the sense that it is presented within the broad framework of assumptions and concepts of the minimalist approach to linguistic inquiry ${ }^{11}$. A distinguishing feature of this approach is its emphasis on the methodological principle of Economy. Hence, the aim is to develop an analysis in which the number of descriptive devices is restricted to the minimum, ideally to those which are conceptually necessary. The general devices of Minimalist Syntax that will be employed in the analysis concern concepts such as '(semantically) interpretable and uninterpretable features', 'valued and unvalued features', 'phi $(\varphi)$-features', 'feature valuation and feature agreement', 'case and theta $(\theta)$-role assignment', 'c-command', 'probe and goal', and the operations External and Internal Merge. In addition, the analysis employs some devices that have been put forward in recent studies of word order and linearisation phenomena in various Germanic languages, including Afrikaans ${ }^{12}$. Unless otherwise stated, these and related devices will be assumed without further discussion. The NSA furthermore incorporates several devices which specifically relate to the establishment of a structural relationship between a reflexive pronoun - or, more broadly, an anaphoric expression - and an appropriate antecedent, and the semantic interpretation of this relationship. These devices form part of the core hypotheses of the NSA, to which we now turn.

\footnotetext{
8 The most influential account of the referential relationships involving anaphors, pronominals and r-expressions has been the Binding theory set out in Chomsky (1981) and developed further in e.g. Chomsky (1982, 1985, 1986) and Chomsky and Lasnik (1993, in Chomsky 1995); cf. also Reinhart and Reuland (1993). Among the more recent accounts are those put forward by Reuland (2001), Kayne (2002), Zwart (2002), Heinat (2005, 2006a, 2006b) and Hicks (2006).

9 For the empirical and conceptual problems faced by GB theory, cf. e.g. Reuland and Everaert (2001), Zwart (2002), Hornstein et al. (2005:ch. 8) and the references cited there.

${ }^{10}$ Besides semantic devices, pragmatic devices drawing on non-linguistic information can also play a role in establishing the interpretation of a reflexive pronoun (or the interpretation of a pronoun as reflexive or nonreflexive) in a given utterance. Evidently, such information is also necessary to determine the referents of expressions that (can) function as antecedents for reflexives. The role of non-linguistic information is briefly addressed towards the end of this section.

${ }^{11}$ Cf. e.g. Chomsky (1995, 2000, 2001, 2004, 2005a, 2005b, 2006), Freidin (1997) and Hornstein et al. (2005).

${ }^{12}$ Cf. e.g. Holmberg (2000), Julien (2002), Biberauer (2003), Biberauer and Richards (2006), Biberauer and Roberts (2006), Biberauer et al. (2009, 2010) and Roberts (2010).
} 
The first two hypotheses, labelled A and B below, are largely taken over from Heinat (2006b) ${ }^{13}$. Hypothesis A concerns the grammatical status of pronouns as "non-reflexive" or "reflexive":

\section{Hypothesis A}

Non-reflexive and reflexive pronouns are syntactic compounds which are formed from the same category-neutral lexical root $\sqrt{ } \mathrm{PRON}^{14}$.

According to this hypothesis, the difference between a non-reflexive and a reflexive pronoun is described in syntactic rather than lexical terms. The specific way in which this difference is established is stated in Hypothesis B:

\section{Hypothesis B}

1. A non-reflexive pronoun is derived by merging $\sqrt{ }$ PRON with an $\mathrm{N}$ constituent that contains interpretable, valued $\varphi$-features and an uninterpretable, unvalued case feature.

2. A reflexive pronoun is derived by merging $\sqrt{ } \mathrm{PRON}$ with a $\mathrm{D}$ constituent that contains interpretable, unvalued $\varphi$-features and an uninterpretable, unvalued case feature.

The distinction between non-reflexive and reflexive pronouns is therefore not determined by lexical features (e.g. [anaphor] and [pronominal], as in Government Binding (GB) theory; cf. fn. 7) or by a feature that is bestowed on a pronoun in a particular syntactic configuration (e.g. [+coreferential], as in Zwart's (2002) analysis; see below), but rather by the category of the item with which $\sqrt{ } \mathrm{PRON}$ is merged. On the one hand, a non-reflexive pronoun is a derived $\mathrm{N}$ which is subsequently merged with a D to form a larger nominal phrase, a DP. On the other hand, a reflexive pronoun is a derived $\mathrm{D}$ representing both the minimal and the maximal projection of the phrase it heads (i.e. $\mathrm{D}=\mathrm{DP}$ ).

Hypotheses A and B can be made concrete with the aid of the sentences in (10) and (11). Sentence (10a) is an example of a non-reflexive construction in which the pronoun is used in a referentially independent way; as shown by the ungrammaticality of (10b), the pronoun cannot be interpreted as coreferential with the subject die man. Sentence (11a), by contrast, is an example of an obligatory reflexive construction with the pronoun taking as its antecedent the subject die man; in this case, the pronoun cannot be used on its own to identify some entity, as is clear from the ungrammaticality of (11b). In terms of Hypothesis B, the pronouns in (10a) and (11a) have the structure in (12a) and (12b), respectively ${ }^{15}$.

\footnotetext{
${ }^{13}$ In connection with Hypothesis B, cf. also Pesetsky and Torrego (2004, 2007).

${ }^{14}$ Heinat's analysis of reflexive and non-reflexive pronouns as syntactic compounds is grounded in the framework of Distributed Morphology, as set out in e.g. Halle and Marantz (1993); cf. also Heinat (2006a:ch. 3; 2006 b:2128 ) and the references cited there. In an earlier analysis, Zwart (2002) also put forward the idea that these two types of pronouns are formed from the same root in the course of a syntactic derivation (cf. the discussion below in the text); Zwart (2002:275) refers to this root as "the generic variable referential element PRONOUN".

${ }^{15}$ Following Kayne (1994), a projecting head is taken to be the leftmost sister at the point of merger; hence the N and the D precede the $\sqrt{ }$ PRON in (12). This is in contrast to the corresponding structures in Heinat $(2005,2006 \mathrm{a}$, 2006b) where the $\sqrt{ }$ PRON precedes the N/D. A more substantive difference with Heinat's approach concerns the nature of what is labelled " $\mathrm{D}$ " in (12b). In the present paper, this D is not understood as encoding the notions 'definiteness' and 'specificity' which are standardly associated with the category D in the generative literature (cf. Abney 1987, Bernstein 2001). The precise nature of the D in (12b) will not be examined here.
} 
(10)

a. Die $\operatorname{man}_{\mathrm{i}}$ haat homj.

the man hates him

"The man hates him"

b. *Die $\operatorname{man}_{\mathrm{i}}$ haat homi.

a. Non-reflexive pronoun

DP

$[\mathrm{v}-\varphi]$

[u-case]
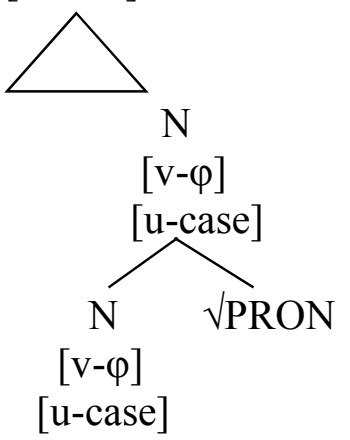

a. Die $\operatorname{man}_{\mathrm{i}}$ haat homself $\mathrm{i}_{\mathrm{i}}$. the man hates himself

"The man hates himself"

b. *Die man $_{\mathrm{i}}$ haat homself

b. Reflexive pronoun

D

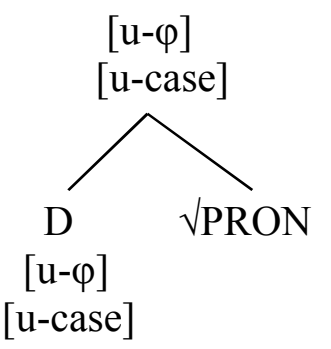

A consequence of Hypothesis B is that a reflexive pronoun, unlike a non-reflexive one, is dependent on an antecedent expression to supply it with $\varphi$-feature values. This raises two questions. The first concerns the respective positions occupied by a reflexive pronoun and its antecedent when they first enter the derivation and also the type of structural relationship between these positions. The second question concerns the way in which $\varphi$-feature valuation is effected.

The initial position of the reflexive pronoun in a sentence like (11a) seems relatively straightforward: the pronoun homself (or more precisely, the nominal expression containing this pronoun) is merged with the verb. However, the initial position of the pronoun's antecedent, the subject die man in (11a), is less obvious. There are at least three approaches that can be considered in this regard. One is that the antecedent is externally merged in the canonical position for subjects, that is, in the specifier position of a transitive light verb, $[\mathrm{spec}, v]{ }^{16}$. In terms of this approach, the structural relationship between the reflexive pronoun and its antecedent is one of c-command: the antecedent c-commands the reflexive ${ }^{17}$. This is, in essence, the type of configuration which is assumed in the various analyses of reflexivity presented within the framework of GB theory, and also in the minimalist analysis proposed by Heinat (2006b). As was noted in section 2, however, such analyses are faced with several conceptual and empirical problems. This raises doubts about, amongst other issues, the merit of adopting the configuration just outlined.

The second approach, put forward by Zwart (2002), is to merge the antecedent and what he calls "the generic variable referential element PRONOUN" (2002:275) in the sisterhood relation in (13), where the PRONOUN is the head of the nominal expression XP and the

\footnotetext{
${ }^{16} \mathrm{Or}$ in the specifier position of TP (or IP) in analyses that predate the Predicate-internal Subject Hypothesis; cf. e.g. Koopman and Sportiche (1991) and Hornstein et al. (2005).

${ }^{17}$ C-command entails the following structural relationship (Chomsky 1995:35): A constituent A c-commands a constituent $\mathrm{B}$ if $\mathrm{A}$ does not dominate $\mathrm{B}$ and every $\mathrm{C}$ that dominates $\mathrm{A}$ also dominates $\mathrm{B}$.
} 
antecedent represents its specifier ${ }^{18}$. According to Zwart (2002:271), the antecedent moves away from the pronoun in the course of the derivation, "a movement necessitated by standard licensing requirements" 19.

\section{[XP [antecedent] [PRONOUN]]}

A core idea of Zwart's analysis is that a generic PRONOUN receives a "nonaccidental" anaphoric (e.g. reflexive) interpretation in the semantic component if, and only if, it is directly merged with an appropriate antecedent in the configuration in (13) (Zwart 2002:284). Another core idea is that the PRONOUN in (13) acquires the feature [+coreferential] from the antecedent, which results in the PRONOUN receiving a specific morphological spellout in the phonological component, namely that of a reflexive pronoun (Zwart 2002:275, 285).

The idea that the PRONOUN in (13) acquires a [coreferential] feature in the course of the derivation is potentially problematic in several respects. Firstly, this feature looks suspiciously like a semantic property rather than a purely formal feature. From a minimalist perspective, the nearest that syntax would come to the concept 'coreferential' would arguably be by means of $\varphi$-features which share the same values and which are structurally linked in some way. Secondly, it seems that the sole purpose of bestowing the feature [+coreferential] on the PRONOUN is to ensure that the latter is morphologically spelled out as a reflexive pronoun. Since the PRONOUN acquires this feature ${ }^{20}$ from the antecedent, a nominal expression, the question arises as to whether it forms part of the general feature make-up of nominal expressions, or whether it is an "independent" feature selected from the Numeration just in case the antecedent happens to have been merged in the configuration in (13). On the one hand, the idea that grammatical features can be selected from the Numeration and added to constituents after they have been merged in a specific configuration, does not seem very plausible; it clearly violates Chomsky's (1995:225) Inclusiveness Condition. On the other hand, if [coreferential] is a general feature of nominal expressions (like case and $\varphi$-features, for example), it should also form part of the feature make-up of a non-reflexive pronoun; after all, such a pronoun can indeed function as the antecedent of a reflexive pronoun, as in (14):

(14) Hyi haat homself

he hates himself

"He hates himself"

Recall, however, that both non-reflexive and reflexive pronouns enter the derivation as generic PRONOUNS in Zwart's analysis. If a non-reflexive pronoun, like hy in (14), contains the feature [+coreferential], this feature must therefore form part of the PRONOUN from which it is derived. By implication, then, the feature also forms part of the PRONOUN in (13) from which the reflexive pronoun is derived. This means that the PRONOUN in (13) already has the feature $[+$ coreferential] and does not have to acquire it from the antecedent. Moreover, since

\footnotetext{
${ }^{18}$ Cf. Kayne (2002) for an analysis along similar lines.

${ }^{19}$ Zwart (2002:284) states that the antecedent in the configuration in (13) "needs to move out of XP into a position in which it may acquire features indicating its argument structure status ('thematic role') and grammatical function ('Case')". As will become clear below, such operations are not posited in the proposed nominal shell analysis.

${ }^{20}$ Or perhaps only its value, if one thinks of features as attribute:value pairs; this is however not a possibility that Zwart addresses.
} 
the antecedent pronoun hy in (14) would also have this feature, one would somehow have to ensure that it is not incorrectly spelled out as a reflexive pronoun.

A third potential problem with Zwart's analysis, related to the one just outlined, concerns the distinction between obligatory non-reflexive and obligatory reflexive constructions such as those illustrated in (15) and (16), respectively. In (15), the pronoun hom occurs as the complement of the inherently non-reflexive verb vergesel ("accompany"); as is clear from the ungrammaticality of (15b), hom cannot be interpreted as coreferential with the subject die man. In (16), by contrast, the pronoun occurs as the "semantically inert" (Büring 2005:22) complement of the inherently reflexive verb misgis ("misjudge"); in this case, hom obligatorily takes the subject die man as its antecedent ${ }^{21}$.

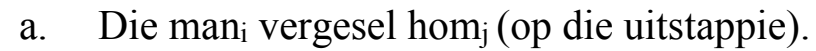

the man accompanies him on the outing

"The man is accompanying him (on the outing)"

b. *Die man $_{i}$ vergesel hom $($ op die uitstappie).

(16) a. Die $\operatorname{man}_{\mathrm{i}}$ misgis hom $\mathrm{i} /$ homself $_{\mathrm{i}}{ }^{22}$

the man misjudges him / himself

"The man is mistaken"

b. * Die man $_{\mathrm{i}}$ misgis hom ${ }_{\mathrm{j}}$.

If the distinction between obligatory non-reflexive and obligatory reflexive constructions is to be accounted for in syntactic terms, the grammar must provide some device to express the fact that a verb like misgis in (16a) has to take a reflexive pronoun as its complement, whereas a verb like vergesel in (15a) cannot. It is generally accepted that such idiosyncratic properties are expressed by means of selection restrictions which form part of a given item's lexical make-up. For example, a verb like misgis would have a selection feature that could informally be stated as "requires a reflexive expression as its syntactic complement". This implies that the (nominal expression containing the) pronoun hom in (16a) must somehow be identifiable as reflexive at the point where it is merged as the complement of misgis. Within Zwart's analysis, hom is semantically interpreted as a reflexive by virtue of occurring in the configuration in (13). However, under the conventional conception of selection restrictions, the verb does not have access to the internal structure of the XP containing hom as its head: it simply selects a particular category as its complement with no obvious way of "knowing" whether this category contains a PRONOUN that has received a reflexive interpretation. It could of course be argued that the $\mathrm{XP}$ in (13) is marked, via feature percolation, as reflexive because of the feature [+coreferential] which is bestowed on its PRONOUN head by the antecedent. However, in view of the potential problematic aspects outlined above in connection with this feature, this does not seem to be an attractive option.

\footnotetext{
${ }^{21}$ Cf. Oosthuizen (2013:ch.2) for the distinction between inherently non-reflexive and inherently reflexive verbs.

22 The pronominal complement of inherently reflexive verbs like misgis is standardly used without the suffix -self. However, the morphologically complex form of the pronoun is commonly (and increasingly) found in everyday speech and also in written texts, a phenomenon which Ponelis (1979:83, 88) ascribes to the influence of English. We return at the end of this section to the alternation between the -self and the -self-less form of the pronoun in constructions containing an inherently reflexive verb.
} 
This brings us to the third approach regarding the initial position of the antecedent, the one which will be pursued in the NSA. Similar to the approach of Zwart (2002), it is claimed that the reflexive pronoun and its antecedent are externally merged in a local configuration, though not in the strict sisterhood sense illustrated in (13). Rather, the idea is that the merger of these two constituents is mediated by some sort of functional category $\mathrm{X}$, with the reflexive merged as the complement and its antecedent as the specifier of this category. The resulting configuration is shown in $(17)^{23}$.

$$
\left.\left[\mathrm{XP}^{2} \text { [antecedent }\right]\left[\mathrm{XP}^{1} \mathrm{X}-\text { reflexive pronoun }\right]\right]
$$

Two questions arise at this point. The first concerns the general category to which the head $\mathrm{X}$ in (17) belongs. Since the influential work of Abney (1987), it has been generally assumed in the literature that all nominal expressions are projections of the (overt or covert) functional category $\mathrm{D}$ (eterminer), with the $\mathrm{D}$ divided into various types (articles, quantifiers, demonstratives, pronouns, etc.), each with its specific c(onstituent)-selection feature ${ }^{24}$. For instance, a definite nominal expression like die man would be analysed as a DP headed by a definite article which c-selects an NP as its complement. More recently, however, Chomsky (2006:17-18) proposed that all definite nominal expressions are $n^{*}$ Ps headed by the functional category $n^{*}$, a so-called "light noun" 25 :

(18) $[\ldots]$ for definite nominal phrases, the head is now $\mathrm{n}^{*}$ (analogous to $\mathrm{v}^{*}$ ) with the complement $[X(Y P)]$. In this case $X=D$. D inherits the features of $n^{*}$, so YP raises to its SPEC, and D raises to $n^{*}$, exactly parallel to $\mathrm{v}^{*} \mathrm{P}$. Therefore, the structure is a nominal phrase headed by $\mathrm{n}^{*}$, not a determiner phrase headed by $\mathrm{D}$, which is what we intuitively always wanted to say; and D is the "visible" head, just as V is the "visible" head of verbal phrases.

Besides capturing the parallelism between verbal and nominal phrases, the idea of a nominal shell $n^{*} \mathrm{P}^{26}$ also implies, in Chomsky's (2006:18) words, that "(b)oth DP and NP are nominal phrases, the natural result". Adopting this idea, it is claimed here that the $\mathrm{X}$ in (17) is a light noun which selects a reflexive pronoun as its complement; this pronoun, with the structure in (12b) above, is internally merged with the light noun in the course of the derivation. Recall from fn. 14 that the $\mathrm{D}$ in (12b) should not be understood as the locus of definiteness and specificity.

\footnotetext{
${ }^{23}$ The term "antecedent" is used in an informal way in (17) to refer to a nominal expression that could potentially enter into a coreferential relationship with the reflexive pronoun. In terms of the analysis proposed below, at this point of the derivation the expression in question has not yet been semantically identified as the antecedent of the reflexive pronoun, that is, in the technical sense, as the expression with which the reflexive is coreferentially linked.

${ }^{24}$ Other pioneering works in this regard include Kuroda (1988), Stowell (1989), Giorgi and Longobardi (1991), Marantz (1995) and Longobardi (1999).

${ }^{25}$ As regards the category $\mathrm{v}^{*}$ referred to in (18), Chomsky (2006:12) states that "verbal phrases are of the form v$\mathrm{VP}$, where $\mathrm{v}$ can be $\mathrm{v}^{*}$, the functional category that heads verb phrases with full argument structure"; he (2005b:10) mentions "transitive and experiencer constructions" as examples of phrases with a $\mathrm{v}^{*}$ as head. In contrast, v forms the head of "unaccusatives and passives", according to Chomsky $(2006: 12,15)$. Cf. also Richards (2007).

${ }^{26}$ For the sake of simplicity, the labels $n / n \mathrm{P}$ and $v / v \mathrm{P}$ are henceforth used in place of $n * / n * \mathrm{P}$ and $v^{*} / v^{*} \mathrm{P}$.
} 
This raises the second question, namely to which specific type of light noun the $X$ in (17) belongs. It is commonly assumed that the general category of light verbs can be classified into various types, including causative, agentive and experiential light verbs ${ }^{27}$. Hence, if $n$ represents the nominal equivalent of a transitive light verb $v$, it could be expected that light nouns also come in different types, depending on the particular grammatical and semantic information which they add to the derivation. One such general type has been proposed by Zeller (2008) in his analysis of the relation between word order and subject-verb agreement in isiZulu and other languages of the Bantu family. In these languages, a subject marker (SM) which belongs to the same noun class as the subject is prefixed to the verb stem in subject-verb constructions. In verb-subject constructions, by contrast, "the verb is prefixed with a non-agreeing default marker from a locative noun class", an expletive element which is in complementary distribution with the SM (Zeller 2008:224) ${ }^{28}$. The two constructions are illustrated by the isiZulu examples in $(19 a, b)$ respectively, both containing an intransitive verb ${ }^{29}$.
a. UJohn u-sebenz-il-e.
John1a SM1a-work-DIS-PST
"John worked"
b. Ku-sebenz-e uJohn. EXPL17-work-PST John1a
"John worked"

(Zeller 2008:228)

(Zeller 2008:229)

Zeller (2008:239) argues that the SM in Bantu is an "anti-focus marker", a pronominal clitic which is "the phonological realisation of an $n^{*}$-head with the feature [- Focus]". A subject expression is formed by merging this head with a DP complement; through feature agreement, the SM doubles the noun class features of the DP and, in this way, explicitly marks the subject as [- Focus]. In Zeller's analysis, the subject $n \mathrm{P}$ in a sentence like (19a), on the one hand, is raised from its initial position in [spec, v] to [spec, T], and the head of this phrase (that is, the SM $u$-) is incorporated into the T where it combines with the (raised) verb stem. In essence, then, subject-verb agreement involves clitic doubling; in Zeller's (2008:227) words, the SM "doubles the subject DP whenever the latter has moved out of the $v \mathrm{P}$ ". In a sentence like (19b), on the other hand, the subject is claimed to contain an $n$-head with the feature [+ Focus]. As a consequence, the subject $n \mathrm{P}$ remains in [spec, v], clitic doubling does not take place and the subject-prefix slot of the verb stem is filled by a default marker, the expletive $k u$-. Support for the claim that the postverbal subject in (19b) is specified as [+ Focus] comes from the fact that it has what is often referred to in the literature as "presentational focus": from an information structure perspective, it introduces a new referent into the discourse ${ }^{30}$. This type of focus reading is not available for the preverbal subject in (19a). However, it is not only presentational focus that can be licensed by the [+ Focus] feature. Zeller (2008:250-1) states that "postverbal subjects are obligatorily marked as [+ Focus] and hence contrastively focused when another

\footnotetext{
${ }^{27}$ Cf. e.g. Kratzer (1996), Baker (2003) and Folli and Harley (2004).

${ }^{28}$ Following Baker (2003), Zeller (2008:224) states that "the expletive is required for purely morphological reasons; it fills the subject prefix-slot and must be attached to the verb stem at PF if no SM is present".

${ }^{29}$ Zeller (2008:fn. 1) provides the following glosses of the grammatical morphemes in (19): SM = subject marker, DIS $=$ marker of the disjoint verb form, PST = (recent) past tense, and EXPL = expletive; the numbers mark specific noun classes in Bantu.

${ }^{30}$ For presentational focus, cf. e.g. Prince (1988), Birner and Ward (1998), Ward and Birner (2001), ErteschikShir (2007), Hartmann (2008), Cruschina (2012) and also the references in fn. 29 of this paper.
} 
argument is realised inside the $v \mathrm{P}^{\prime{ }^{31}}$. In the isiZulu example in (20), which contains both a subject and an object in postverbal position, the subject receives a contrastive focus reading ${ }^{32}$ :

\author{
Kumbe uJohn igolide. \\ EXPL17-dig-PST John1a gold9 \\ "John dug (for) gold"
}

In short, the presence of an SM in subject-verb constructions in Bantu, and its absence in verbsubject constructions, can be accounted for in terms of a specific feature carried by the head of the subject $n \mathrm{P}:$ [-Focus] in the case of preverbal subjects and [+ Focus] in the case of postverbal subjects.

It is not the purpose of this discussion to determine the merit of Zeller's (2008) account of subject-verb agreement in Bantu ${ }^{33}$. However, what is of relevance for the development of the NSA is the idea that a light noun can form the locus of some sort of focus property. In Zeller's framework, this property is represented by the feature [Focus], which can have either a positive or a negative (i.e. "anti-focus") value. The [+ Focus] feature furthermore configurationally licenses two different types of focus interpretations, namely presentational and contrastive focus. Adopting the idea presented above, it is proposed here that the head $n$ in the configuration in (17) also expresses a focus property of some sort. Obviously, though, the property in question cannot be contrastive focus in the case of an obligatory reflexive construction, like the one illustrated in (16a), since this construction contains only one proper argument, the reflexive being semantically inert. Also, at least as far as the reflexives in (11a) and (16a) are concerned, the property is evidently not presentational in nature as, in these cases, the reflexive does not introduce a new entity into the discourse. Rather, the type of focus that seems to be relevant in the configuration in (17) is one which may be called "identity focus": the use of the reflexive draws attention to the relationship of referential identity between the subject and the syntactic object of the verb ${ }^{34}$. The idea, then, is that this function is formally expressed by means of an $n$-head containing a focus feature with the value "identity" (henceforth, [id-focus]). Moreover, it is proposed here that the identity focus $n$-head is the locus of the-self affix which is spelled out as part of the reflexive pronoun in sentences like (11a), where the merger of these two elements is effected by D-to- $n$ raising in accordance with Chomsky's proposal in (18). Being a nominal element, it seems reasonable to assume that the $n$ also contains, at least, $\varphi$-features and

\footnotetext{
${ }^{31}$ Informally stated, contrastive focus serves to identify or emphasise one entity from a set of (explicitly stated or contextually implied) alternatives for which a proposition holds true. Cf. e.g. Rochemont (1986), Rochemont and Culicover (1990), É. Kiss (1998), Gundel (1999), Roberts (1998), Kenesei (2005) and the references in fn. 28.

32 Example provided by Marianna Visser (p.c.).

${ }^{33}$ For an alternative account, cf. Halpert (2012).

${ }^{34}$ Ponelis (1979:81-83) and Heinat (2006a:91) state that the morphologically complex form of the pronoun indicates emphasis rather than reflexivity. Zwart (2002:273) likewise argues that -self represents a focus marker; for supporting evidence from English diachronic data, cf. Keenan (2009). Being a focus marker does not imply, however, that -self is actually used in present-day speech to express emphasis, unless, of course, it is spoken with primary stress. Rather, from a synchronic perspective, it is likely that -self represents a heavily bleached focus marker which originally served to emphasise the coreferential relationship between a reflexive and its antecedent. Note that this view does not affect the identity focus analysis proposed in the text since identity focus does not need to be emphatic.
} 
a case feature, though these features are unvalued at the point where the $n$ is merged into the structure $^{35}$.

The main ideas of the above discussion - that is, Chomsky's (2006) ideas about a nominal shell $n$ P, Zeller's (2008) idea that the $n$-head can express a focus property, and the ideas put forward just now about the function and feature make-up of the $n$ in the configuration in (17) - can be presented as follows in the form of four further hypotheses of the NSA ${ }^{36}$ :

\section{Hypothesis C}

A reflexive and its antecedent are externally merged within the same nominal shell $n \mathrm{P}$ as, respectively, the complement and the specifier of an identity focus light noun $n$.

\section{Hypothesis D}

The $n$ in the configuration $\left[n \mathrm{P}^{2}\right.$ [antecedent $]\left[{ }_{n} \mathrm{P}^{1} n\right.$ - reflexive pronoun] contains

(i) the feature [id-focus], and

(ii) a set of $\varphi$-features and a case feature, which have to be valued in the course of the derivation.

\section{Hypothesis E}

The identity focus $n$ in the configuration in Hypothesis D is the locus of the affix -self.

\section{Hypothesis F}

The reflexive pronoun in the configuration in Hypothesis D undergoes D-to- $n$ raising; that is, it is internally merged with the $n$.

As suggested above, the identity focus $n$-head expresses the notion that the reflexive in the configuration in Hypothesis D serves to emphasise the relationship of referential identity - or, as it is usually referred to, coreferentiality - between the reflexive and its antecedent. The question that needs to be addressed next is exactly how this relationship is established. In this regard, consider again the obligatory reflexive construction in (11a) Die man haat homself, where the pronoun hom is analysed as a D with the structure in (12b). According to Hypotheses $\mathrm{C}-\mathrm{E}$, this pronoun is externally merged as the complement of a light noun which contains the features [id-focus], [u- $\varphi$ ], [u-case] as well as the affix-self; and according to Hypothesis F, the pronoun is subsequently merged with the $n$-head, creating an object that is eventually spelled out as homself. The resulting structure is given in (21). Since the $\varphi$-features of both the pronoun and the $n$ are unvalued, no $\varphi$-feature valuation can take place in this configuration. (It is assumed here that D-to- $n$ raising involves a copy-merge operation. This operation is indicated by means of a solid arrow in (21), and the copy left behind by means of outline font; these conventions will be used in all similar structures below. The notation REFL PRON is used to indicate that the item eventually spelled out as the reflexive pronoun hom(self) has not yet been supplied with the appropriate values for its case and $\varphi$-features.)

\footnotetext{
${ }^{35}$ The proposal in (18) suggests that the $n$ could also serve to express definiteness; alternatively, it is possible that this property is expressed by a separate light noun. Cf. Chomsky (2006) for the idea that $n$ forms the locus of the case feature of a nominal expression. The link between case and definiteness/specificity is particularly striking in languages which display definiteness/specificity-driven differential object marking. In Turkish, for example, a non-specific object is unmarked for case, contrasting with a specific object which necessarily bears an accusative marking (cf. Öztürk 2008).

${ }^{36}$ As in the case of (15), the term "antecedent" is used in an informal way in Hypotheses C and D; cf. fn. 22.
} 


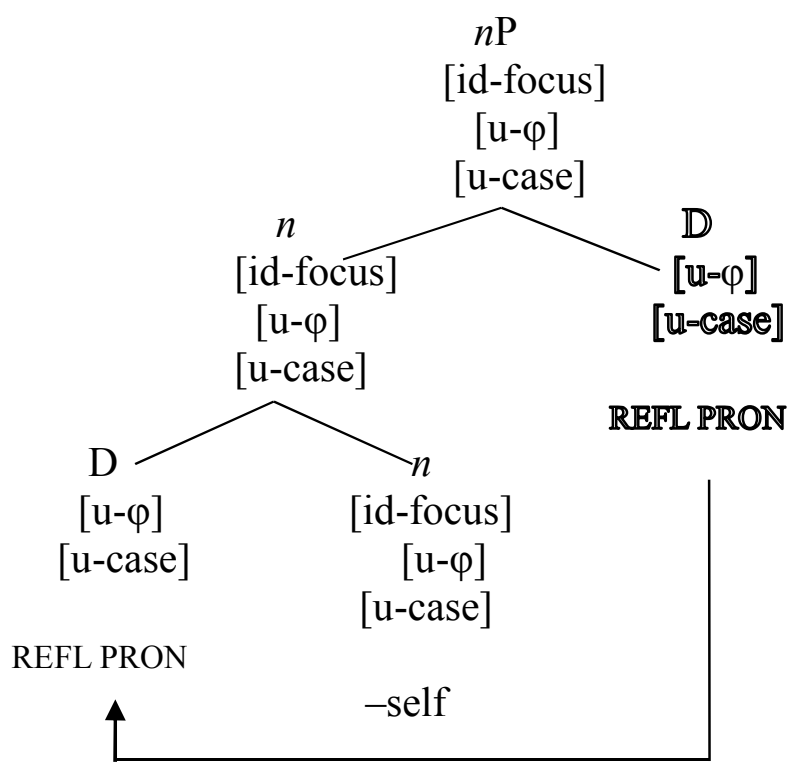

It could be objected that the operation illustrated in (21) is superfluous since the D apparently only "remerges" with the $n$. Note, however, that this structure represents the canonical configuration for incorporation, where the features of the element that is incorporated (or "remerged", in this case the D) form a subset of those of the incorporation host (here, the $n$ ); see Baker (1988) and Roberts (2010) for detailed discussions of various types and the theoretical underpinnings of incorporation phenomena.

Consider next the nominal expression die man functioning as the subject in (11a). In terms of the proposal quoted in (18), this expression is also analysed as an $n \mathrm{P}$, with die man forming the DP complement of a light noun, and the noun man in turn forming the complement of the D die. In this case, the light noun initially contains at least the features $[\mathrm{u}-\varphi]$ and [u-case], but not [id-focus] since it is not selected to express a relationship of referential identity. Furthermore, both the $\mathrm{D}$ and the $\mathrm{N}$ initially contain an unvalued case feature as well as $\varphi$-features; in contrast to the $\mathrm{D}$, however, the $\mathrm{N}$ enters the derivation with its $\varphi$-features already valued (here, 3-pers, sg-num, mas-gen). Note that merger of the $\mathrm{D}$ die and the $\mathrm{N}$ man results in a probe-goal configuration in which the $\mathrm{N}$ can supply the D with the relevant $\varphi$-feature values ${ }^{37}$. Similarly, merger of the DP die man with the light noun brings about a configuration in which the $\varphi$ features of the $n$ can be supplied with the values associated with this particular DP. The whole $n \mathrm{P}$ thus ends up having the $\varphi$-feature values initially provided by the $\mathrm{N}$ man. Given that the $\mathrm{D}$ is raised to the $n$-head, the structure of the $n \mathrm{P}$ die man can be represented as in (22). (Here, and in similar structures below, feature valuation and percolation of feature values within a particular projection are indicated by means of dotted arrows; features that have been valued in the course of the derivation are underlined.)

\footnotetext{
${ }^{37}$ Cf. Chomsky (2000:122-6, 2001:3-6, 2004:113-114) for the concepts 'probe' and 'goal'. It is assumed in this study that phrases containing an unvalued feature(s) can also function as probes, alongside heads. For arguments in support of this view, cf. Heinat (2006a:ch. 2) and the references cited there.
} 


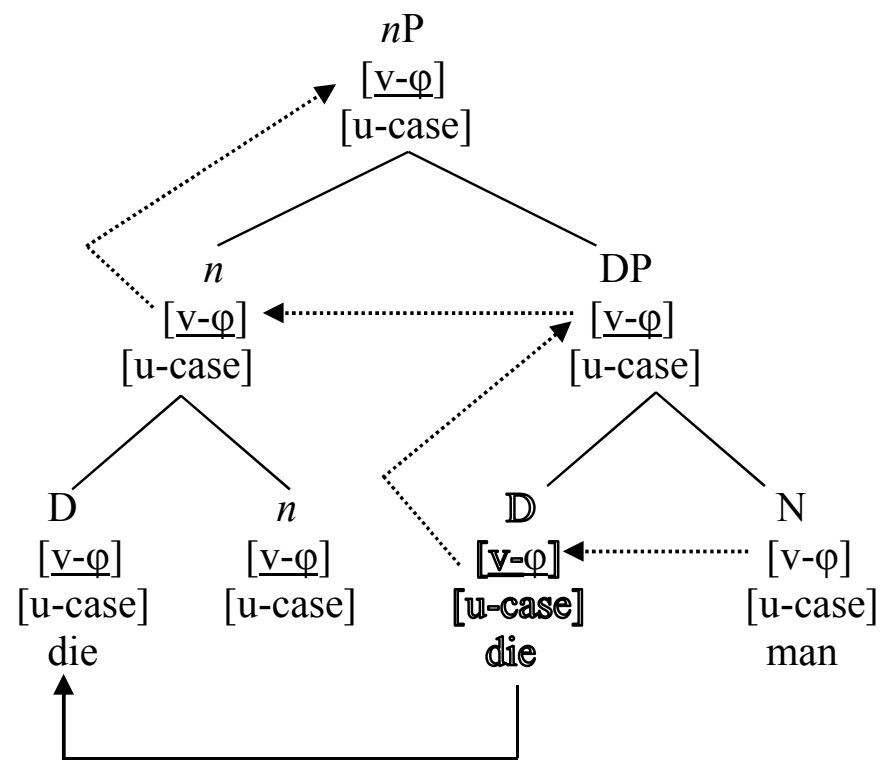

In terms of Hypothesis $\mathrm{C}$, the $n \mathrm{P}$ described in (22) is merged as the specifier of the identity focus $n$ in (21). This sets up a probe-goal configuration in which the $\varphi$-features of the identity focus $n$ (and via percolation, its projections as well) can be valued by the $n \mathrm{P}$ die man. As a consequence, the reflexive pronoun, which is active because of its unvalued case and $\varphi$-features, can now acquire $\varphi$-feature values from the identity focus $n$, in effect the same values as that of the corresponding features of the $n \mathrm{P}$ die man (i.e. 3-pers, sg-num, mas-gen). In short, then, the $\varphi$-features of the reflexive pronoun are indirectly valued by the expression die man, with the identity focus $n$ functioning as intermediary. The various merger and feature valuation operations are shown in (23) below. (For ease of reference, the different light nouns and their respective projections are distinguished by means of numeral subscripts.)

It is proposed here that the structure in (23), with $\varphi$-feature valuation effected in the manner indicated by the dotted arrows, represents the syntactic configuration that is required for establishing an obligatory coreferential relationship between a reflexive pronoun and an antecedent expression. In the case of the sentence in (11a), then, this means that homself is interpreted as obligatorily coreferential with die man at the point where the semantic component gets access to the structure in $(23)^{38}$. It must be emphasised that this interpretation follows solely from the fact that the reflexive pronoun and die man occur in the particular configuration in (23) and have the same $\varphi$-features with the same values; specifically, the semantic device that is responsible for providing the coreferential (or anaphoric) interpretation has no way of "knowing" that the $\varphi$-features of the pronoun were (indirectly) valued by its antecedent in the course of the derivation.

\footnotetext{
${ }^{38}$ There seem to be two ways in which the devices of the semantic component can "get access" to a particular syntactic structure. The conventional view in Minimalist Syntax is that chunks of syntactic structure are transferred to the semantic component at specific stages in the derivation, specifically at every stage where a socalled "phase" has been completed (Chomsky 2001, 2005b). Another possibility is that semantic devices simply come into play at any given point where a structure contains sufficient information to be semantically interpreted. This issue will be left open here.
} 


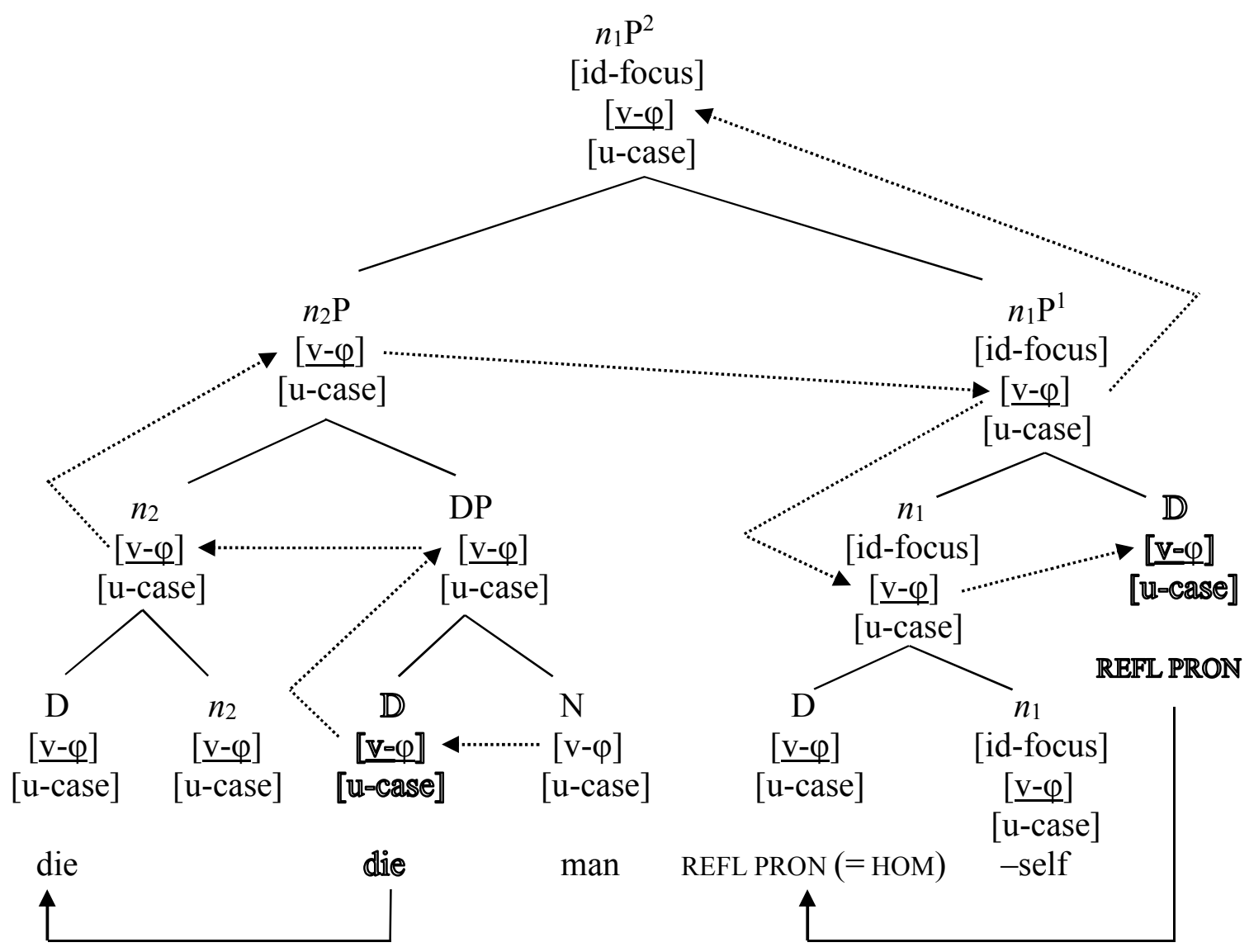

The above proposals about $\varphi$-feature valuation and the semantic interpretation of the configuration described in (23) are captured by the following two hypotheses of the NSA:

\section{Hypothesis G}

In the configuration

$$
\left.\left[n 1 \mathrm{P}^{2}\left[n_{2} \mathrm{P}\right]\left[n 1 \mathrm{P}^{1}\left[[\mathrm{D} \text { reflexive pronoun }]+n_{1}\right] \text { [D reflexive pronoun }\right]\right]\right]
$$

(i) the $n_{2} \mathrm{P}$ values the $\varphi$-features of the $n_{1}$ and its projections and, as a consequence,

(ii) the $n_{1}$ values the $\varphi$-features of the $\mathrm{D}$.

\section{Hypothesis $\mathbf{H}$}

The $\varphi$-valued D in the configuration in Hypothesis $G$ is semantically interpreted as a (reflexive) anaphor and the $n_{2} \mathrm{P}$ as its antecedent; that is, the $\mathrm{D}$ is interpreted as obligatorily coreferential with the $n_{2} \mathrm{P}$.

We now turn to the question of where the identity focus $n \mathrm{P}$ presented in (23) is merged in the structure underlying the sentence in (11a). It was claimed at the beginning of this section that (the nominal expression containing) the reflexive pronoun homself is merged with the verb. According to Hypotheses C, E and F, the pronoun hom is initially merged as the complement of an identity focus $n$ and is subsequently raised to this head where it combines with the affix -self; in other words, the reflexive forms part of an identity focus $n \mathrm{P}$. Hence this claim may be reformulated as follows: in a reflexive construction like the one in (11a), the verb - in this case haat, which is not inherently reflexive but which can be used with a reflexive reading - selects as its complement a nominal expression that is headed by an $n$ with the feature [id- 
focus], that is, an identity focus $n \mathrm{P}$ with the structure in (23). Moreover, it is claimed that the selection of such an $n \mathrm{P}$ is obligatory in the case of inherently reflexive verbs, like misgis in (16a). By contrast, from a grammatical point of view, a non-reflexive construction is one in which the verb does not select an identity focus $n \mathrm{P}$ as its complement. This non-selection of the $n \mathrm{P}$ in question is determined by the lexical properties of the specific verb: either (i) the verb is inherently non-reflexive, like vergesel in (15a), or (ii) the verb also allows a non-reflexive reading, like haat in (10a). These claims can be expressed in the form of the following hypothesis ${ }^{39}$ :

\section{Hypothesis I}

1. A reflexive construction is derived when an identity focus $n \mathrm{P}$ - as represented by the $n_{1} \mathrm{P}^{2}$ in Hypothesis $\mathrm{G}-$ is selected as the syntactic complement of a verb, where the verb is either inherently reflexive or compatible with a reflexive reading.

2. A non-reflexive construction is derived when an identity focus $n \mathrm{P}$ is not selected as the syntactic complement of a verb, where the verb is either inherently nonreflexive or compatible with a non-reflexive reading.

In grammatical terms, then, a "reflexive construction" is defined as one in which the verb selects an identity focus $n \mathrm{P}$ as its complement (obligatorily in the case of inherently reflexive verbs like misgis). Conversely, a "non-reflexive construction" is grammatically defined as one in which the verb does not (or cannot, as in the case of inherently non-reflexive verbs like vergesel) select an identity focus $n \mathrm{P}$ as its complement ${ }^{40}$. It is assumed here - based on the proposals in e.g. Holmberg (2000), Julien (2002), Pesetsky and Torrego (2007) and Biberauer et al. (2009) - that the selection of a specific type of complement is formally expressed in the form of a constituent selection feature ([c-select]) of the particular head. For instance, an inherently reflexive verb like misgis would have a [c-select] feature to the effect that this verb requires an identity focus $n \mathrm{P}$ as its complement; this feature is deleted as part of the merger operation ${ }^{41}$.

Returning to the derivation of the sentence in (11a) Die man haat homself, the structure resulting from the merger of the verb haat and the identity focus $n \mathrm{P}$ in (23) can be represented as in (24). There are three points in connection with the structure in (24) that require comment. The first concerns the ordering of the verb and its complement. The account of word order and linearisation that is assumed in this study is largely based on the framework developed by, amongst others, Biberauer and Richards (2006), Biberauer and Roberts (2006), Biberauer et al. (2009) and Roberts (2010). In terms of this framework, the complement is merged to the right of the verb in Germanic varieties, including Afrikaans. The second point concerns the verbal or V-related features carried by the verb (as opposed to nominal or D-related features such as case, $\varphi$ - and $\theta$-features). These are taken to include a $[+\mathrm{V}]$ categorial feature, an unvalued tense feature ([u-tense]), and a [c-select] feature.

\footnotetext{
${ }^{39}$ As shown in Oosthuizen (2013), prepostions, like verbs, can also be divided into those that are either inherently reflexive or compatible with a reflexive reading, and those that are either inherently non-reflexive or compatible with a non-reflexive reading. He (2013:section 3.2.2) accordingly provides a generalised version of Hypothesis I which refers not only to verbs, but to prepositions as well.

${ }^{40}$ At the end of the present section, attention will also be given to a construction that may be described as "pragmatically reflexive".

${ }^{41}$ Deleted features are henceforth indicated by means of strikethrough, as in (24).
} 
(24)

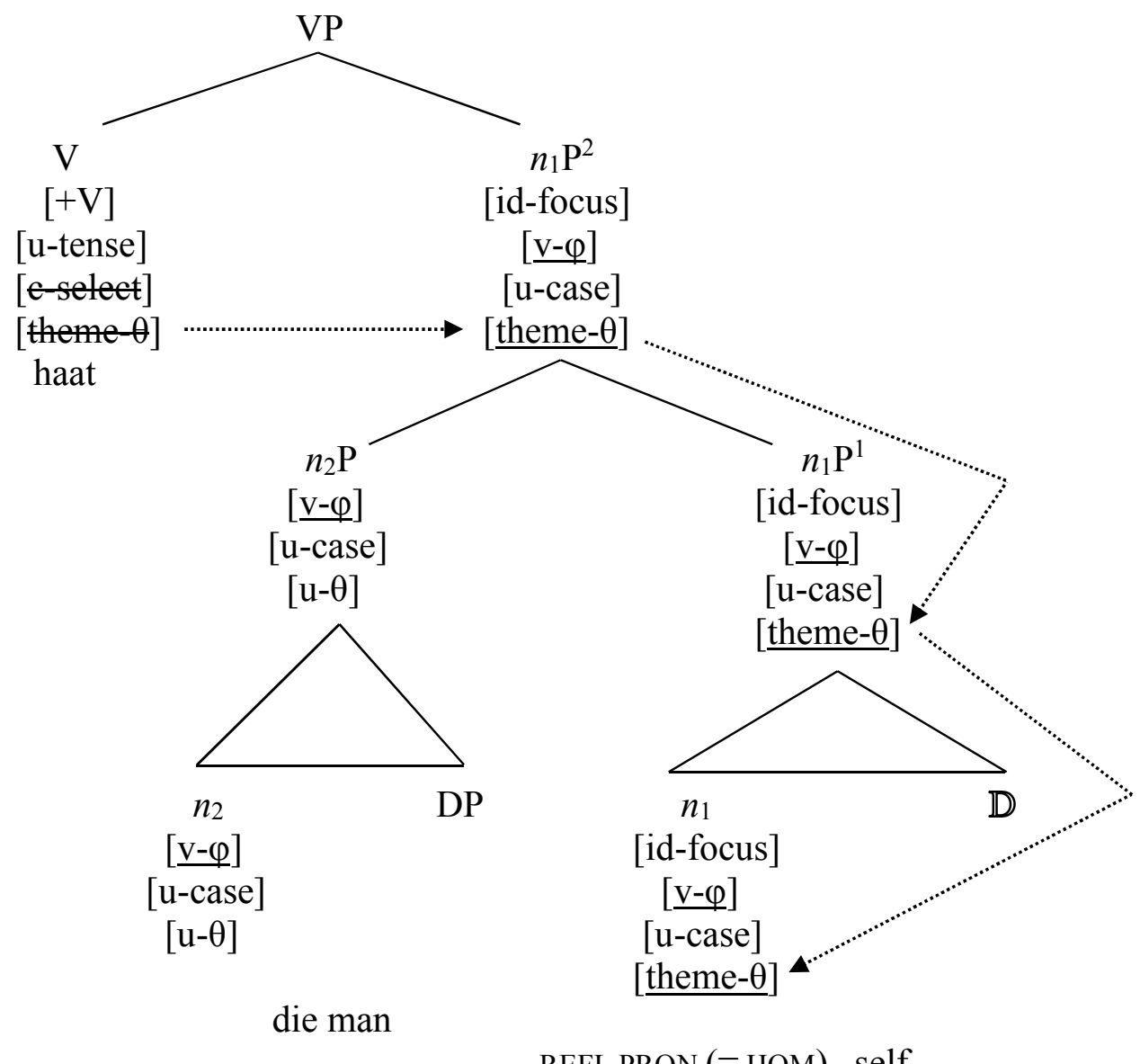

The third point in connection with (24) concerns the $\theta$-roles carried by the nominal expressions in (11a). The expression die man represents the experiencer and homself the theme. Focusing for the moment on homself, it is a standardly held view that a lexical verb which selects a nominal expression as its complement is involved in the assignment of a $\theta$-role to that expression. In the case of (11a), then, haat would enter into the process whereby the theme role is assigned to its $n \mathrm{P}$ complement, which has the reflexive homself in head position. However, it is not clear exactly how and by means of which formal devices this process is effected. One possibility - based on proposals by, amongst others, Fanselow (2001), Hornstein (1999), and Manzini and Rousseau (2000) - would be along the following lines. Firstly, both the light noun $n$ and the verb contain a $\theta$-feature which is interpretable but unvalued in the case of the $n$ and uninterpretable but valued (e.g. [theme- $\theta$ ]) in the case of the verb. Secondly, the verb supplies the relevant value to the $\theta$-feature of its $n \mathrm{P}$ complement (and, via percolation, to every other instance of this feature on the projection line of the identity focus $n$ ). Thirdly, the verb's $\theta$ feature, being uninterpretable, is deleted in the process of valuing the corresponding feature of the $n \mathrm{P}^{42}$. Furthermore, on this account, the $\theta$-feature of the identity focus $n_{1}$ and its two projections in (24) - i.e. $n_{1} \mathrm{P}^{1}$ and $n_{1} \mathrm{P}^{2}$ - becomes syntactically "inert" after it has been valued, which means that this feature is not visible for further syntactic operations. By contrast, the $\theta-$ feature of the nominal expression in the specifier position of the $n_{1} \mathrm{P}^{2}-$ which does not form part of the projection line of the identity focus $n_{1}$ - remains visible for agreement purposes since it is still unvalued. The discrepancy between the "activeness" of the $\theta$-feature associated with

${ }^{42}$ In connection with $\theta$-role assignment, cf. also Lee-Schoenfeld (2007) and Boeckx et al. (2010). 
the $n_{1} \mathrm{P}^{2}$ in (24) and that of the subject $n_{2} \mathrm{P}$ die man in the specifier position of the identity focus $n$ immediately explains why there is no A-over-A-type complication in this case ${ }^{43}$. In short, the verb haat $\theta$-values the structurally closest goal in its c-command domain, that is, the $n_{1} \mathrm{P}^{2}$, thereby rendering this $n \mathrm{P}$ inert from a $\theta$-valuation perspective. This means that (the unvalued $\theta$-feature of) the subject $n_{2} \mathrm{P}$ constitutes the closest goal for any subsequent $\theta$-probe.

The next step in the derivation of (11a) is to merge the VP in (24) with a light verb that carries the V-related features $[+\mathrm{V}]$, [c-select] and [u-tense]. This creates the structural setting for several further operations, one being that the lexical verb is raised to the $v^{44}$. The second has to do with the assignment of accusative case to the complement of the lexical verb haat, that is, to the identity focus $n_{1} \mathrm{P}^{2}$ in (24). It is widely assumed that structural case assignment is effected via feature agreement in a probe-goal configuration and, more specifically, that $v$ represents a probe which determines accusative case-marking of a nominal expression in its c-command domain $^{45}$. Being a probe implies that the $v$ must contain at least one unvalued feature, which is taken to be $[u-\varphi]$ (where " $\varphi$ " stands for a cluster of features such as person, number and gender). Given these assumptions, it is claimed here that (i) the $\varphi$-features of the $v$ are valued by the $\varphi$ features of the identity focus $n \mathrm{P}$ in (24), and (ii) the $v$ carries an accusative case feature ([acccase]) which serves to value the case feature of this $n \mathrm{P}$. Since the two case features and the $\varphi$ features of the $v$ are uninterpretable, they are deleted as part of the valuation process. Note that the $n \mathrm{P}$ headed by the identity focus $n$ becomes inactive from a probe-goal perspective once its case feature has been valued since it does not contain any other unvalued features; the $n \mathrm{P}$ die man in its specifier position is still active, however, because of its unvalued case and $\theta$-features.

The third operation concerns the $\theta$-marking of the expression die man in (11a). The commonly held view is that light verbs are involved in the assignment of a $\theta$-role to a nominal expression that functions as the semantic subject of a sentence. Pursuing the ideas about $\theta$-features put forward above, it could be claimed that - similar to a lexical verb such as haat in (24) - a light verb contains an uninterpretable, valued $\theta$-feature and that this feature serves to value the corresponding feature of an $n \mathrm{P}$ in the c-command domain of the $v$. In the case of (11a), die man functions as the subject of the sentence; in (24), it forms part of the identity focus $n_{1} \mathrm{P}^{2}$, and it moreover contains an unvalued $\theta$-feature. The following is now proposed: the $v$ probes the VP in (24) in search of an appropriate nominal expression to which it can assign the value of its $\theta$ feature. Recall that the identity focus $n \mathrm{P}$ has already been $\theta$-valued by the verb haat, whereas its specifier, the $n_{2} \mathrm{P}$ die man, still has an unvalued $\theta$-feature. Hence the $v$ provides the $n_{2} \mathrm{P}$ with a specific $\theta$-value, in this case experiencer (represented as $[\exp -\theta])^{46}$. Of course, if the VP that is probed by the $v$ lacks a nominal expression that has not yet been $\theta$-valued, the $v$ would have to search for one outside of the structure which it c-commands, where such an expression would

\footnotetext{
${ }^{43}$ Put simply, the A-over-A Condition (and its more recent incarnation, Minimality) states that in a structure such as $\left[\mathrm{B}\left[\mathrm{A}_{1}\left[\mathrm{~A}_{2}\right]\right]\right]$, where $\mathrm{B}$ can ambiguously enter into a grammatical relationship with either $\mathrm{A}_{1}$ or $\mathrm{A}_{2}$, the relationship must involve the higher, more inclusive element $A_{1}$. Cf. e.g. Chomsky (1964), Kayne (1994), Boeckx and Hornstein (2007), Hornstein (2009) and Roberts (2010).

${ }^{44}$ Adopting the approach of Marantz (1997) and Chomsky (2004:122), Biberauer and Roberts (2006:282) characterise V-to- $v$ raising as "a standard and possibly universal operation". Cf. also Myler (2009).

${ }^{45}$ Cf. e.g. Hornstein et al. (2005) and Chomsky (2006).

${ }^{46} \mathrm{Cf}$. the comments about the A-over-A Condition above in the text and in fn. 43. Cf. e.g. Richards (2011) for the idea that a structure (specifically, a phase) is spelled out as soon as it can be, in other words, at the point where all the features contained in that structure have been valued.
} 
then be externally merged as a specifier of the light verb ${ }^{47}$. In the derivation of (11a), however, such an external search is not called for; and in any case, here the lexical subarray feeding the derivation of the $v$-phase does not contain any other nominal constituent that could be externally merged into the specifier position of the $v \mathrm{P}$.

The fourth operation following from the merger of a light verb with the VP in (24) concerns the fact that the subject and the object, in this order, precede the lexical verb in subject-initial clauses in Afrikaans, except in V2 constructions, such as main clauses which lack an auxiliary verb, and subordinate clauses which lack both an auxiliary verb and an overt complementiser. The subject-object-verb ordering is illustrated by the examples in (25):

a. Die man het homself gehaat.

the man has himself hated

"The man hated himself"

b. Ek weet dat die man homself haat.

I know that the man himself hates

"I know that the man hates himself"

In terms of the framework assumed here, the ordering in (25) is brought about by raising the $\mathrm{VP}$ into the specifier position of the $v \mathrm{P}$; moreover, this is taken to be a general option in Afrikaans, one which is also involved in the derivation of subject-initial V2 constructions ${ }^{48}$. In the case of (11a), then, raising of the VP into the specifier position of the $v \mathrm{P}$ will result in both the subject and the object preceding the verb haat which, at this stage, occupies the $v$-head position.

An obvious question at this point is what triggers the VP raising operation. In accordance with the probe-goal approach to feature agreement and movement developed by numerous researchers since Chomsky $(2000,2001)$ and Pesetsky and Torrego $(2001,2004)$, it is assumed here that the raising operation in question is triggered by an Edge Feature (which may be thought of as a generalised EPP-feature) that is associated with the $\varphi$-features of the probe $v^{49}$. Following Biberauer et al. (2008), such movement triggers may be formally represented by means of the diacritic ${ }^{\wedge}$ which is appended to the relevant features. In the derivation under discussion, then, raising of the VP is an Agree-related operation triggered by the movement diacritic associated with the light verb's $\varphi$-features, that is, $v\left[\mathrm{u}-\varphi^{\wedge}\right]^{50}$. It must however be noted that, at least in the case of (11a), raising of the VP containing the identity focus $n \mathrm{P}$ in (24) and raising of this $n \mathrm{P}$ on its own will result in the same linear ordering of the subject die man, the object homself and the verb haat. In other words, in this case there does not seem to be a clear reason for preferring an analysis on which the VP is pied-piped along with the $n \mathrm{P}$ over one

\footnotetext{
${ }^{47}$ In terms of Rizzi's (2007) proposals, the second option would correspond to "external search" whereas the more conventional probing operation would instantiate "internal search".

${ }^{48}$ Cf. e.g. Biberauer (2003, 2009), Biberauer and Roberts (2005), Biberauer et. al. (2008), Biberauer et al. (2009), Biberauer and Roberts (2010) and Roberts (2010).

${ }^{49}$ It remains to be clarified whether the movement diacritic is associated with one or more specific $\varphi$-features (i.e. person, number or gender) or with the cluster of $\varphi$-features. Oosthuizen (2013:section 3.2.4) argues that some light verbs and the non-finite $T$ are "defective" in the sense that they contain only one of the $\varphi$-features in question, namely number, and that the ${ }^{\wedge}$ is associated with this single feature.

${ }^{50}$ For Agree, cf. Chomsky (2000, 2001). Biberauer and Roberts (2010:13) provide the following definition: (i) $\alpha$ Agrees with $\beta$ where: (a) $\alpha$ asymmetrically c-commands $\beta$, and (b) there is no $\gamma$ non-distinct in formal features from $\alpha$ such that $\gamma$ c-commands $\beta$ and $\alpha$ c-commands $\gamma$.
} 
where the VP is left stranded, that is, where the $n \mathrm{P}$ is raised on its own. Although the piedpiping analysis will be adopted for the purposes of this study, both of these options seem to be available in Afrikaans. Such an approach might well provide a basis for explaining various "leaking" phenomena, that is, cases where VP-related constituents can occur either to the left or to the right of the lexical verb. For example, it could then be argued that a sentence like (26a) is derived by pied-piping the VP along with the raised object, whereas (26b) is derived by raising only the object, resulting in the PP staying behind as a "leaked" constituent in the stranded $\mathrm{VP}^{51}$.

(26) a. Hy het die pasiënt na 'n spesialis verwys.

he has the patient to a specialist refer

"He referred the patient to a specialist"

b. Hy het die pasiënt verwys na 'n spesialis.

he has the patient refer to a specialist

"He referred the patient to a specialist"

The various operations brought about by the merger of the VP in (24) with an experiencer light verb are illustrated in (27).

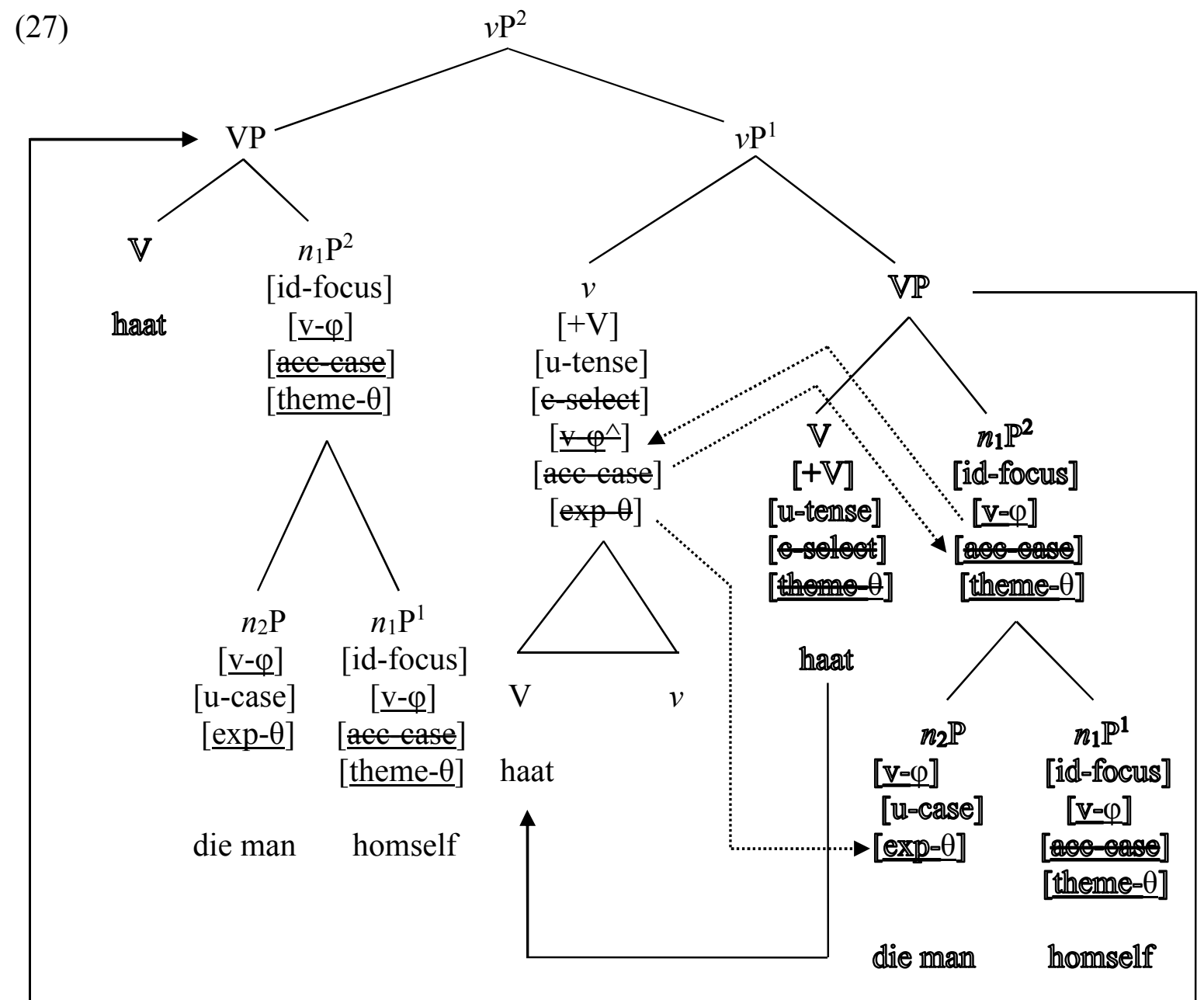

${ }^{51} \mathrm{Cf}$. Biberauer (2003) for an analysis of such leaking phenomena in Afrikaans. 
Continuing with the derivation of (11a), the $v \mathrm{P}$ in (27) is merged with a T-head containing the $\mathrm{V}$-related features [c-select], unvalued [V], and valued [tense]. By entering into a probe-goal relation with the $v / \mathrm{V}$, the $\mathrm{T}$ acquires a positive value for its categorial feature $([+\mathrm{V}])$ and at the same time supplies a value for the tense feature of the $v / \mathrm{V}$, in this case present ([pres-tense]). In the analysis proposed here, the $\mathrm{T}$ also has two types of $\mathrm{D}$-related features, one being unvalued $\varphi$-features. With regard to the other type of D-related feature, the standard view is that finite $\mathrm{T}$ enters into the assignment of nominative case, and that this is effected by means of feature agreement. Similar to the analysis above of accusative case assignment, the $\mathrm{T}$ is therefore assumed to have a nominative case feature ([nom-case]). These D-related features enter into an agreement relationship with the corresponding features of a nominal goal in the T's c-command domain. As noted above, the $n \mathrm{P}$ headed by the identity focus $n$ cannot enter into any agreement relations because all of its features have been valued at this stage. However, the $n_{2} \mathrm{P}$ forming part of the raised VP in (27), that is, the subject die man, is an active goal because of its unvalued case feature (although it might well contain other unvalued features as well; see below). Hence the $\mathrm{T}$ supplies the $n \mathrm{P}$ die man with the nominative case value and concurrently acquires $\varphi$ values from the $\varphi$-features carried by this $n \mathrm{P}$. Furthermore, in terms of the account of word order and linearisation assumed here, the T's $\varphi$-features - like those of the $v$ in (27) - are associated with a movement trigger which causes the $n \mathrm{P}$ die man to raise into the specifier position of the TP. As in the case of object raising, this operation is taken to involve pied-piping of both of the phrases containing the expression die man - that is, the $n \mathrm{P}$ headed by the identity focus $n$ and the $v \mathrm{P}$ dominating this $n \mathrm{P}$ - resulting in the whole $v \mathrm{P}$ being raised. In other words, the subject is not raised on its own and neither is the verb independently raised to the $\mathrm{T}$ head. However, similar to what was suggested in connection with object raising, it is possible that there are at least two options available regarding raising of the subject: (i) either the $v \mathrm{P}$ is piedpiped along with the subject (as is claimed here to be the case in standard varieties of Afrikaans), or (ii) the subject is raised on its own to the specifier position of the TP, with the $v / \mathrm{V}$ independently raised to the T-head. The second option could well provide an account for the fact that, in colloquial Afrikaans and also in some non-standard varieties such as Kaaps, the finite verb can occur between the subject and the object in subordinate clauses with an overt complementiser, as illustrated in (28b) and (29b) below. In such cases, it could then be argued that the object forms part of the stranded VP. This possibility will however not be examined further here (cf. Biberauer 2003, 2009; Biberauer and Richards 2006 for discussions).

(28) a. Ek weet dat hy die boek gelees het.

I know that he the book read has

"I know he read the book"

b. Ek weet dat hy het die boek gelees. (non-standard)

(29) a. Ek weet dat die man homself haat.

I know that the man himself hates

"I know that the man hates himself"

b. Ek weet dat die man haat homself.

(non-standard)

The effects of the various operations resulting from the merger of the $\mathrm{T}$ with the $v \mathrm{P}$ in (27) are shown in (30). 
$(30)$

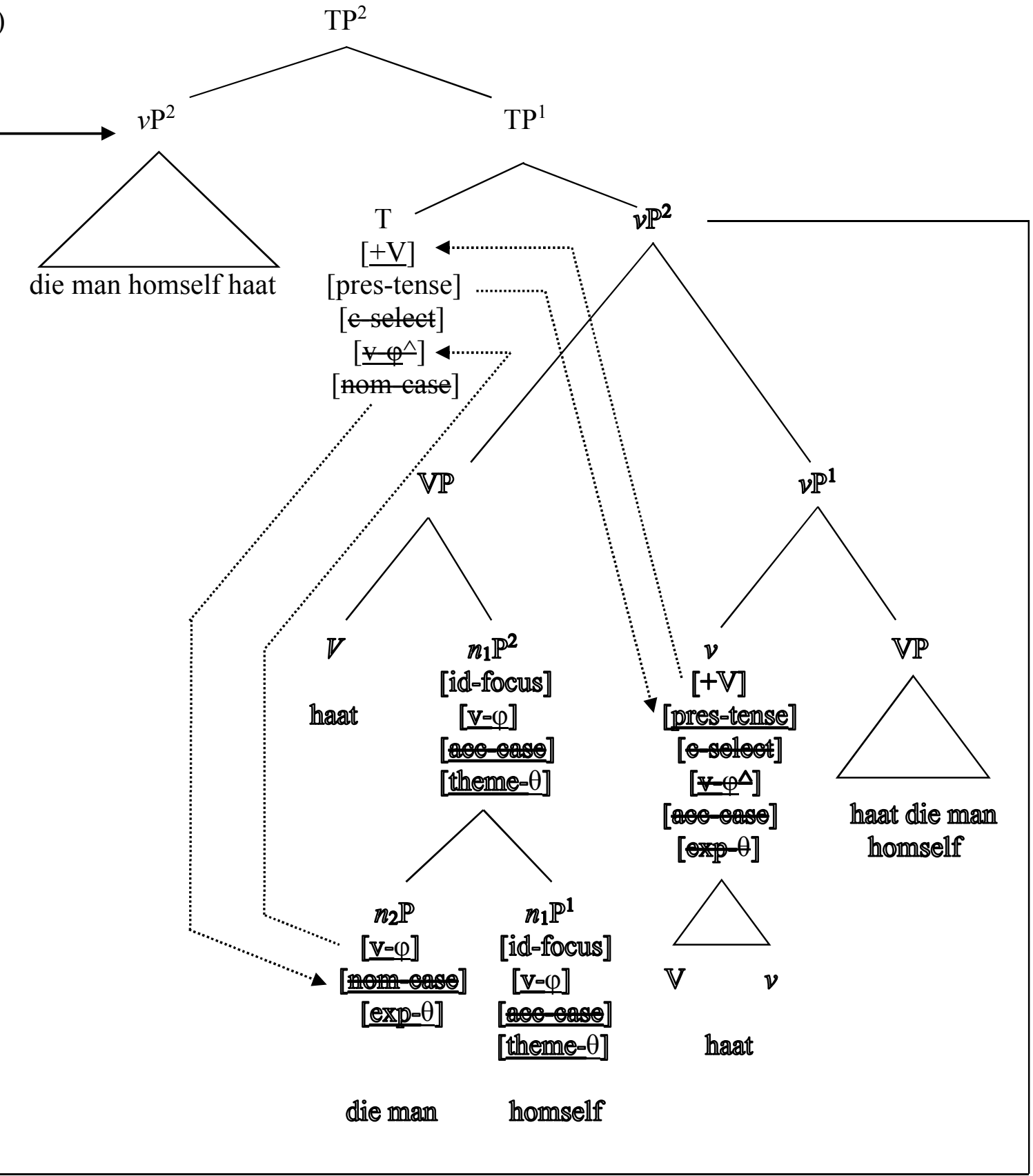

The final stage in the derivation of (11a) starts with the merger of the $\mathrm{TP}^{2}$ in the structure in (30) with a C-head ${ }^{52}$. In order to derive the surface V2 order of (11a) from the subject-objectverb order displayed in (30), two movement operations have to take place: (i) the subject die man must raise to the specifier position of the $\mathrm{CP}$, and (ii) the finite verb haat must raise to the $\mathrm{C}$; at this stage, the subject (i.e. $n_{2} \mathrm{P}$ ) and the verb (i.e. $v / \mathrm{V}$ ) both form part of the $v \mathrm{P}^{2}$ in $[\mathrm{spec}$,

\footnotetext{
${ }^{52}$ According to Rizzi's (1997) Split-CP hypothesis, the left-periphery is the locus of various inflectional and discourse-related features, each associated with a specific head (Force, Top(ic), Foc(us), Fin(iteness)). Cf. also Benincà and Poletto (2004), Paoli (2006) and, for Afrikaans, Botha and Oosthuizen (2009). For the sake of simplicity, this expansion of the CP into several layers of functional heads will not be incorporated into the present discussion.
} 
$\mathrm{T}]^{53}$. In the framework adopted here, subject raising and $v / \mathrm{V}$-raising are triggered by two movement diacritics, one associated with a D-related feature of the $\mathrm{C}$ and the other with a Vrelated feature. However, it is not clear exactly which features are carried by the $\mathrm{C}$ and with which features the movement diacritics are associated. Some possibilities are outlined below but, because of the speculative nature of the discussion, no firm conclusions will be drawn.

Consider first the subject-raising operation. For this to take place, the $n_{2} \mathrm{P}$ die man in (30) must have an unvalued feature to ensure that it is active for probe-goal purposes, and the $\mathrm{C}$ must likewise have an unvalued D-related feature - with a movement diacritic - which can be valued by the $n_{2} \mathrm{P}$ and which can trigger subject raising. Note however that the $n_{2} \mathrm{P}$, as represented in (30), does not contain an unvalued feature, which suggests that it is not active. Moreover, it is not clear which D-related feature of the $\mathrm{C}$ could enter into a probe-goal relation with a corresponding feature of the subject. There are various possible ways of overcoming these potential problems. One possibility is that both the $\mathrm{C}$ and the subject $n_{2} \mathrm{P}$ have a discourserelated feature which is unvalued and bearing a movement diacritic in the case of the $\mathrm{C}$, and valued in the case of the subject. Since it is plausible that the subject die man represents the topic of the sentence in (11a), it could be claimed on the basis of the proposals put forward by Aboh (2010) that the $n_{2} \mathrm{P}$ has the feature [topic-disc(ourse)] which serves to value the [u-disc] feature of the $\mathrm{C}^{54}$. However, this still leaves the problem of the $n_{2} \mathrm{P}$ being an inactive goal. In this regard, it could be argued that the $n_{2} \mathrm{P}$ is visible from a probe-goal perspective simply by virtue of forming part of some other visible goal, in this case the raised $v \mathrm{P}^{2}$ in (30) (an issue to which we return below). Alternatively, it could be argued that the T-head - contrary to what was assumed above - does not in fact carry the nominative case feature in Afrikaans, but that this feature is actually contained in the $\mathrm{C}$-head ${ }^{55}$. This would mean that the subject $n_{2} \mathrm{P}$ will still have an unvalued case feature at the stage where it is raised along with the $v \mathrm{P}^{2}$ into the specifier position of the TP, making it an active goal that can be case-valued by the $\mathrm{C}$. These and other possibilities will not be examined further here. Rather, it is simply assumed for the purposes of the present paper that (i) subject raising is brought about by a movement diacritic associated with an unvalued discourse-related feature of the $\mathrm{C}$, and (ii) the subject is somehow visible as a goal for the C-probe.

Consider next the $v / \mathrm{V}$-raising operation. For this to take place, the $\mathrm{C}$ must have an unvalued $\mathrm{V}$-related feature with a movement diacritic. A likely candidate would be the categorial feature [V]. Note that the $\mathrm{T}$ in (30) is inactive since all its features have been valued either in the formation of the lexical array (e.g. [pres-tense] and [nom-case], if $\mathrm{T}$ is taken as the locus of this case feature; see above), or by means of feature agreement (e.g. $\varphi$-valuation by the subject $n^{2} \mathrm{P}$ and [V] valuation by the $v / \mathrm{V}$, both prior to $v \mathrm{P}$ raising). Hence the $\mathrm{T}$ cannot serve to value the $[\mathrm{u}-\mathrm{V}]$ feature of the $\mathrm{C}$. This leaves the $v / \mathrm{V}$ which, it must be noted, also seems to be inactive from a probe-goal perspective. A possible solution - similar to the one suggested above in connection with the locus of nominative case - would be to regard the $\mathrm{C}$ as the locus of the

\footnotetext{
${ }^{53}$ Cf. e.g. Vikner (1995) and Biberauer and Roberts (2006). For an early analysis involving movement of the subject into the CP domain, cf. Den Besten (1977).

${ }^{54} \mathrm{It}$ is left open here whether such a discourse-related feature is linked to the $\varphi$-feature complex of the $n$-head or whether it defines a further structural layer inside the subject $n \mathrm{P}$, that is, a projection headed by a distinct topic$n$ which is analogous to the Top-head postulated by Rizzi (1997) within the extended CP domain.

${ }^{55}$ For the idea that the $\mathrm{T}$ receives its features from the C, cf. Chomsky (2004, 2005b). Ouali (2008) distinguishes Donate and Share as two types of feature transfer. Cf. also Biberauer and Roberts (2010).
} 
valued tense feature in Afrikaans, rather than the $\mathrm{T}$ as was previously assumed ${ }^{56}$. This would mean that the $v / \mathrm{V}$ in the raised $v \mathrm{P}$ in (30) is still unvalued for tense, making it an active goal. As a consequence, the [pres-tense] feature of the C could value the tense feature of the $v / \mathrm{V}$ and the $v / \mathrm{V}$ could value the $[\mathrm{u}-\mathrm{V}]$ feature of the $\mathrm{C}$, with the movement diacritic associated with the $\mathrm{C}$ 's $\mathrm{V}$ feature triggering $v / \mathrm{V}$-raising. The obvious question, of course, is why the whole $v \mathrm{P}^{2}$ in (30) is not pied-piped along with the $v / \mathrm{V}$, resulting in the $v \mathrm{P}$ being raised to a second specifier position of the CP. Although this could conceivably be a parameterised option (perhaps involved in the derivation of some OVS orders), it will be assumed here that Agree-driven raising which is related to categorial features only targets a head since it is the head that defines the categorial status of a particular projection. In the case of (11a), then, it is the raised head $v / \mathrm{V}$ which specifies the verbal nature of the $\mathrm{C}^{57}$. Note that, as in the case of subject raising, these ideas are simply presented as possibilities that require further investigation.

The structure resulting from the merger of the $\mathrm{TP}^{2}$ in (30) with a $\mathrm{C}$ is illustrated broadly in (31). For the sake of simplicity, and in view of the speculative nature of the above discussion, the various features and valuation operations which could be involved in the derivation are not indicated.

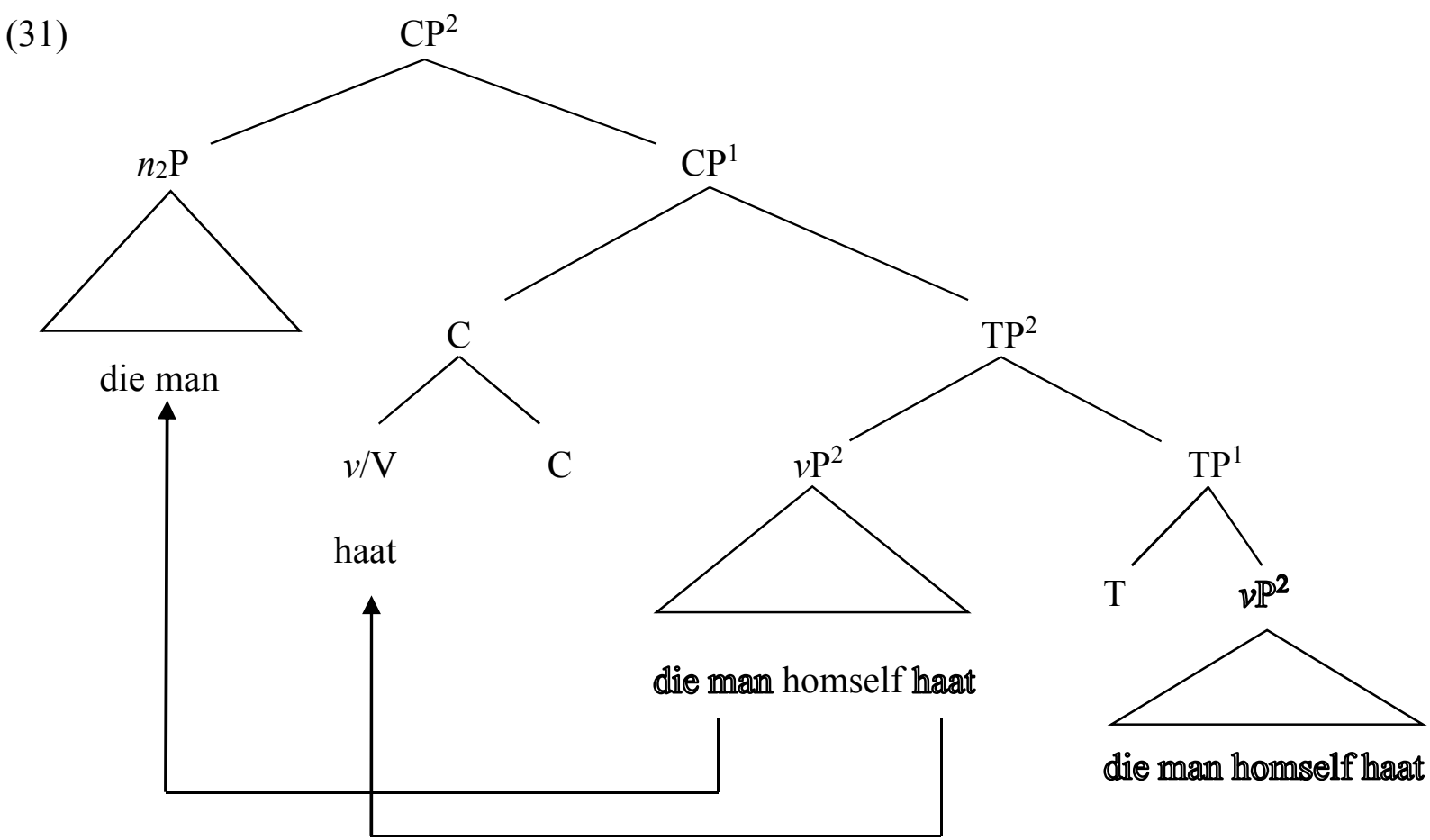

Let us now briefly examine the three other types of construction referred to at the beginning of this section, namely those illustrated by the sentences in (10a), (15a) and (16a). Consider first the reflexive sentence in (16a) Die man misgis hom. There are three salient differences between this sentence and the reflexive sentence in (11a) Die man haat homself. The first is that misgis in (16a) is an inherently reflexive verb, which means that it is semantically intransitive in the sense that it lacks a complement functioning as an argument, yet at the same time syntactically

\footnotetext{
${ }^{56} \mathrm{Cf}$. the references in $\mathrm{fn} .55$ in connection with $\mathrm{C}$-to- $\mathrm{T}$ feature spreading. The idea of a $\mathrm{T}$ entering the derivation without a tense specification does seem rather counter-intuitive, however.

${ }^{57}$ Cf. e.g. Holmberg (1986) and Vikner (1995) for the idea that Cs are both verbal and nominal in nature.
} 
transitive in that it obligatorily selects a reflexive as its complement. This is in contrast to haat in (11a) which is not only semantically transitive, but also compatible with both a reflexive and a non-reflexive interpretation of its pronominal complement, as shown in (10a). Even so, in terms of Hypothesis I, an inherently reflexive verb and one which is not inherently reflexive but which is used with a reflexive reading, both select an identity focus $n \mathrm{P}$ as their syntactic complement. The derivation of (16a) therefore proceeds in essentially the same manner as that proposed above for (11a).

The second difference concerns the morphological form of the reflexive pronoun. In Afrikaans, the reflexive is standardly used without the suffix -self when it is selected by an inherently reflexive verb, although - self forms are commonly found with such verbs in everyday speech and also in written texts ${ }^{58}$. By contrast, with a verb like haat the reflexive reading is only possible when the morphologically complex form of the pronoun is used, as shown by the difference in grammaticality between $(10 \mathrm{a}, \mathrm{b})$. According to Hypothesis E, the identity focus $n$ head is the locus of the affix -self. However, in a sentence like (16a) the $n$ is not required to carry this affix, most likely because the meaning of the inherently reflexive verb misgis makes it superfluous to emphasise the coreferential relationship between the subject and the verb's complement by means of an overt identity focus marker. Conversely, such a marker is required in the case of a sentence like (11a) because the meaning of haat allows both a reflexive and a non-reflexive reading; in other words, here the affix -self serves to emphasise the fact that the verb is used in a reflexive construction.

The third difference concerns the $\theta$-roles which are assigned to the various nominal expressions in (11a) and (16a). In (11a), the subject die man and the reflexive homself represent the experiencer and the theme, respectively. In (16a), die man is also interpreted as the experiencer, but here the reflexive hom is semantically inert in the sense that it lacks a specific $\theta$-role; that is, it does not function as a distinct argument. It was suggested above that a nominal expression carries an unvalued $\theta$-feature and that this feature is valued by an appropriate head in a probegoal configuration. For instance, in (11a) the experiencer light verb values the $\theta$-feature of the subject $n \mathrm{P}$, whereas the lexical verb haat supplies the theme value for the object $n \mathrm{P}$ headed by the identity focus $n$. Pursuing this idea, the $\theta$-feature of the subject die man in (16a) is likewise assigned the experiencer value by the light verb. However, being semantically inert, the object homself in this construction is apparently not assigned a $\theta$-value by the inherently reflexive verb misgis. One would therefore expect the derivation to crash since the object is left with an interpretable but unvalued $\theta$-feature. This is not the case, however. Maintaining the idea that the object does indeed have an unvalued $\theta$-feature when it is merged with the lexical verb, a

\footnotetext{
${ }^{58}$ Ponelis $(1979: 83,88)$ ascribes the increasing use of the -self form of the reflexive, particularly in utterances with inherently reflexive verbs, to the influence of English. When such utterances are spoken with the normal, non-emphatic sentence stress pattern, the verb standardly receives the primary stress (cf. Jan verSET hom teen die aanval, "John is resisting the attack"). However, when the complex form of the reflexive is used, the utterance can also be spoken with the primary stress on -self (cf. Jan verset homSELF teen die aanval). Ponelis (1979:81-3) claims that - self serves to strengthen ("versterk") the pronoun, that is, to bring about an emphatic form of the pronoun, in utterances where the verb is not inherently reflexive. Generalising this claim, it is likely that - self is used in such cases to provide emphasis, specifically, to turn the pronoun into an emphatic form. If this is true, it would be contrary to Büring's (2005) claim that "semantically inert arguments, as found with inherently reflexive verbs, cannot bear emphasis" (p. 23) and show an "inability to be stressed" (p. 22, fn. 20). Like Ponelis (1979:81-83) in the case of Afrikaans, Heinat (2006a:91) claims that "the 'self'-morpheme indicates emphasis and not reflexivity". Zwart (2002: 273) argues that "anaphors can be analyzed as pronouns with added focus markers", where -self represents such a focus marker; this idea is incorporated into the NSA in the form of Hypotheses E and F.
} 
possible solution is to postulate that an inherently reflexive verb has the property of assigning a null value to the $\theta$-feature of its syntactic complement ([null- $\theta])$, thereby grammatically marking the nominal expression as semantically inert. This would mean that the object homself in (16a) is in fact $\theta$-valued, albeit in a "vacuous" manner. On this approach, then, an inherently reflexive verb could be defined in grammatical terms as one which (i) obligatorily selects an identity focus $n \mathrm{P}$ as its complement, and (ii) assigns a null value to the $\theta$-feature of this $n \mathrm{P}$. Similarly, a semantically inert nominal expression could be grammatically defined as one which has been assigned a null $\theta$-value.

Consider next the sentence in (15a) Die man vergesel hom (op die uitstappie). Vergesel is an inherently non-reflexive verb: it belongs to a subclass of semantically transitive verbs which can select a pronominal expression as its complement, but which disallows a reflexive interpretation for this expression, as shown by the difference in grammaticality between $(15 a, b)^{59}$. In terms of Hypothesis I, vergesel in (15a) therefore lacks the ability to select an identity focus $n \mathrm{P}$ as its syntactic complement. This entails that the object hom and the subject die man do not form part of the same nominal shell, the one represented by the $n_{1} \mathrm{P}^{2}$ in Hypothesis G. Rather, as outlined in the structure in (32) below, the verb vergesel selects (an $n \mathrm{P}$ containing) a non-reflexive pronoun (that is, hom, with the structure in (12a)), whereas die man is externally merged into the canonical position for subjects, namely a specifier position of the light verb ${ }^{60}$. In accordance with Hypothesis $\mathrm{H}$, hom in (15a) therefore cannot be interpreted as a (reflexive) anaphor taking die man as its antecedent.

This brings us to the non-reflexive sentence in (10a) Die man haat hom. It was noted above that the verb haat is compatible with both a reflexive and a non-reflexive interpretation of its pronominal complement, but that the reflexive interpretation is only possible when the pronoun occurs with the suffix -self, as in (11a). In other words, with the subclass of semantically transitive verbs to which haat belongs, the morphologically simplex form of the pronoun indicates that the verb is used with a non-reflexive reading. According to Hypothesis I, the fact that haat is used non-reflexively in (10a) means that it does not select an identity focus $n \mathrm{P}$ as its syntactic complement. This entails that the object hom and the subject die man are not externally merged as, respectively, the complement and the specifier of an identity focus $n$ head. Rather, as in the derivation of (15a), the verb haat in (10a) selects (an $n \mathrm{P}$ containing) the non-reflexive pronoun hom (that is, a pronoun with the structure in (12a)), whereas the subject die man is externally merged as a specifier of the light verb. In short, then, die man and hom do not form part of the identity focus configuration described in Hypothesis G. It is therefore correctly predicted in terms of Hypothesis $\mathrm{H}$ that hom in (10a) cannot be interpreted as coreferential with the subject die man.

\footnotetext{
${ }^{59}$ Afrikaans contains at least two subclasses of verbs where the reflexive interpretation is normally disallowed. The first comprises verbs which express movement of one entity relative to another (usually also moving), with the former remaining in a position before, after or alongside the latter or changing from one of those positions to another. The verbs of the second subclass express some sort of action by one entity on another, possibly involving physical contact, and causing the latter to move away from or towards the former. Cf. Oosthuizen (2013:section 2.3.1) for a discussion.

${ }^{60}$ Various raising and agreement operations are involved in the derivation of the $v \mathrm{P}$ associated with (15a), including V-to- $v$ raising, VP raising into the (first) specifier position under the $v \mathrm{P}$, and several instances of feature-valuation. For ease of presentation, the effects of these operations are not indicated in (32).
} 


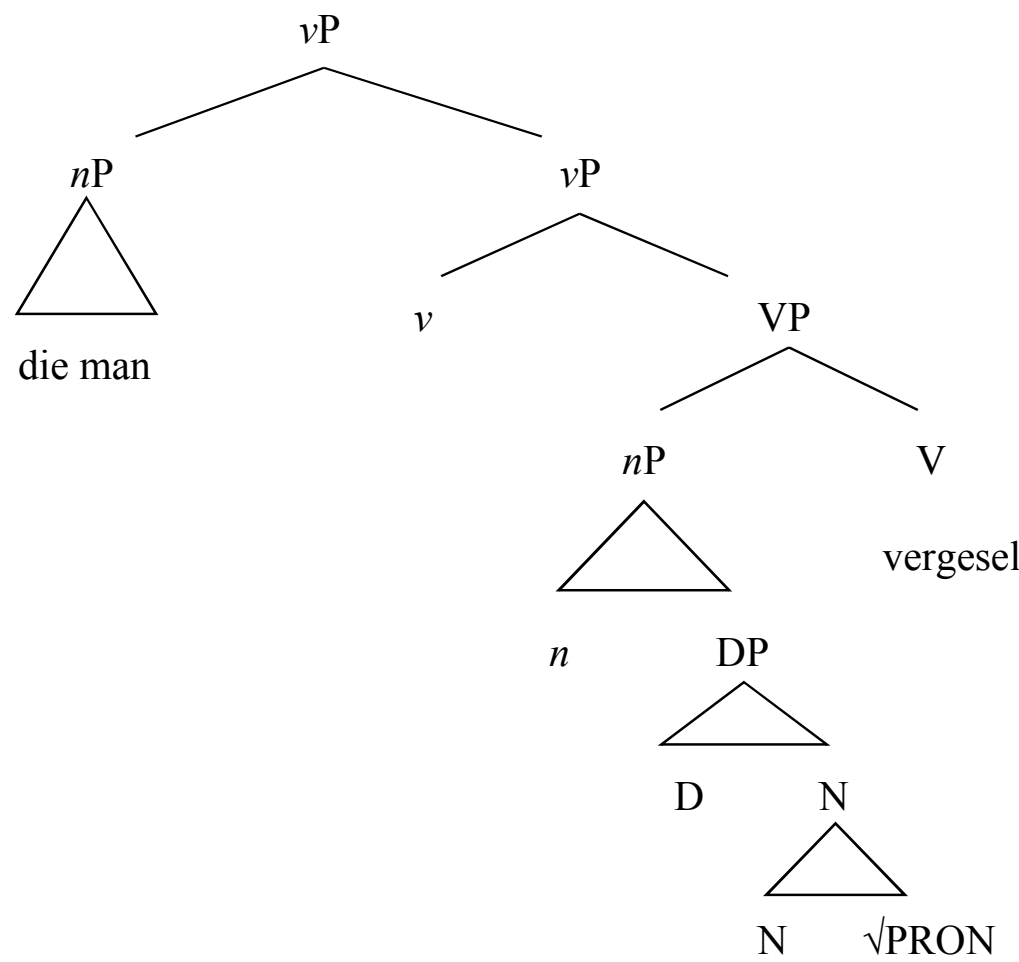

hom

Two other verbal object complement constructions require comment at this juncture. The first of these is illustrated by the following sentences:

(33) a. Die man skeer homself $_{\text {i }}$ (elke oggend).

the man shaves himself every morning

"The man shaves himself (every morning)"

b. Die mani $_{\text {skeer hom }}$ (elke oggend).

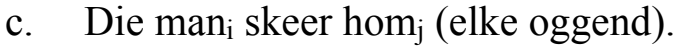

The verb skeer in (33) is similar to haat in that, although not inherently reflexive, it allows a reflexive interpretation for its pronominal complement. With haat the reflexive interpretation is only possible, and is in fact obligatory, when the pronoun occurs with the suffix -self. With a verb like skeer, the reflexive interpretation is also obligatory when the complex form of the pronoun is used. It could thus be argued that skeer, like haat, selects an identity focus $n \mathrm{P}$ as its complement in those cases where it is used with an obligatory reflexive reading, that is, when skeer occurs with the -self form of the pronoun as in (33a). However, with skeer the reflexive interpretation is also an option with the simplex form of the pronoun, as shown in (33b). In other words, a sentence such as Die man skeer hom is ambiguous between a reflexive and a non-reflexive interpretation of the pronoun. Notice, though, that there are no linguistic considerations which could provide a basis for establishing a reflexive interpretation in this case: (33b) does not contain the identity focus marker -self and the verb does not express an inherently reflexive meaning. From a grammatical perspective, then, a sentence like (33b) cannot be defined as "reflexive" in the sense that the verb selects an identity focus $n \mathrm{P}$ as its complement. Rather, it seems likely that the subject die man and the pronoun hom are externally merged as, respectively, the specifier of the light verb and the complement of the lexical verb, 
similar to the structure in (32). However, this does not imply that a coreferential relationship is necessarily ruled out between the subject and the pronoun; after all, the expressions die man and hom have the same $\varphi$-feature values, although these values have been independently acquired from the lexical array. What is instead claimed here is that such a relationship cannot be established on purely grammatical grounds, that is, in terms of Hypotheses $\mathrm{G}$ and $\mathrm{H}$. Following Sperber and Wilson (1995:10), it could plausibly be argued that the option of interpreting the pronoun as reflexive or non-reflexive is brought about by "an interaction between linguistic structure and non-linguistic information, only the former being dealt with by the grammar". On this approach, a sentence such as (33b) is therefore not "grammatically reflexive" in the sense of Hypothesis I, but rather "pragmatically reflexive" in the sense that non-linguistic information is crucially involved in establishing the coreferential relationship between the subject and the pronoun. Since such a relationship is not obtained in the case of (33c), this sentence is non-reflexive on both grammatical and pragmatic grounds.

The second of the constructions requiring discussion concerns sentences such as the one in (16a) above, repeated here for convenience:

a. Die mani $_{\mathrm{i}}$ misgis homi $/$ homself . $_{\text {. }}$

the man misjudges him

"The man is mistaken"

Afrikaans does not overtly distinguish between strong and weak pronouns in the sense of Cardinaletti and Starke (1999). However, there is evidence that this distinction is real, as seen in the domain of inherently reflexive verbs such as misgis in (16a). The complement selected by verbs of this type is in some sense a "dummy": the only choice is a pronominal, which (i) has to be coreferential with the agent argument, and (ii) bears a null $\theta$-role that renders it "semantically inert". An important observation about the pronominal complement of an inherently reflexive verb is that it cannot receive primary stress, as shown in (34).

$$
\text { Die man misgis hom / *HOM. }
$$

As described in Oosthuizen (2013:section 2.3.1), the pronominal complement of an inherently reflexive verb is also subject to restrictions relating to fronting, coordination and right-node raising ${ }^{61}$. Taken together, these characteristics render it plausible that the pronominal complement in question is a weak pronoun. Further evidence supporting this proposal comes from Cinque's (1993) syntax prosody mapping analysis in terms of which the object within the VP receives default stress. Strikingly, however, the pronominal object of an inherently reflexive verb may not be stressed. If, as proposed above, the pronominal complement of such verbs is in fact a weak pronoun, these facts follow straightforwardly. Returning to the alternation between morphologically simplex and morphologically complex forms of the pronoun in the

\footnotetext{
${ }^{61}$ For example, as shown in the respective examples in (i), the pronominal complement of an inherently reflexive verb like gedra ("behave") cannot be fronted in a passive construction, coordinated with another (pro)nominal expression, or right-node raised.

(i) a. *Homi is gedra deur $\operatorname{Jan}_{i}$.

him was behaved by Jan

b. $*^{*} J_{a n}$ gedra hom ${ }_{i}$ en haar/Marie/die meisie.

Jan behaves him and her/Marie/the girl

c. * $\operatorname{Jan}_{\mathrm{i}}$ gedra en Pieter $_{\mathrm{j}}$ haat hom . $_{\text {. }}$

Jan behaves and Pieter hates him
} 
structure at hand, as shown in (16a), it is claimed here that the morphologically complex -self forms in Afrikaans can only contain strong pronouns, a claim which receives support from the diachronic development of complex reflexives in West Germanic languages (Keenan 2009). It follows, therefore, that the form homself in (16a) is necessarily a spellout of a strong pronoun plus the identity focus head, the locus of -self. In other words, Afrikaans does not contain a distinct form consisting of a weak pronoun plus -self. As a result, speakers of Afrikaans appear to be employing two forms when expressing obligatory reflexivity in structures containing an inherently reflexive verb: (i) the more conservative option of a weak pronoun without-self, and (ii) the more colloquial option (likely influenced by English; cf. Ponelis 1979) of a strong pronoun plus -self.

In this section, the content of the proposed nominal shell analysis of obligatory reflexivity was presented in the form of nine hypotheses which relate to (i) the establishment of a structural relationship between a reflexive pronoun and an appropriate antecedent, and (ii) the semantic interpretation of such a relationship. The devices of the NSA were explicated with reference to several reflexive (as well as non-reflexive) constructions in Afrikaans, specifically those in which the pronoun occurs as the object complement of a verb. In analysing these constructions, various additional proposals were made about, amongst others, grammatical features, case assignment, $\theta$-role assignment and Agree-related movement. It should be emphasised that these proposals have not been presented as core hypotheses of the NSA, but simply as working hypotheses about the course of syntactic derivations in Afrikaans; a discussion of their potential flaws and merits falls outside the scope of this paper.

\section{Summary and conclusion}

The main objective of this paper was to make explicit the assumptions and devices of a novel minimalist analysis of obligatory reflexivity in Afrikaans. The proposed nominal shell analysis (NSA) takes as its point of departure the idea that two expressions which enter into an obligatory coreferential relationship are initially merged together in a particular nominal shell structure. It was argued that the nominal shell in question is headed by an identity focus light noun, a functional category which belongs to a natural class of identificational (or quantificational) elements. This light noun takes the reflexive as its complement and the antecedent as its specifier. The antecedent values the $\varphi$-features of the reflexive, with the identity focus $n$ serving as mediator.

The question throughout was whether the NSA is (i) empirically adequate in the sense that it can account for the relevant facts of Afrikaans, and (ii) conceptually adequate in the sense that it incorporates theoretical devices which are either provided by or compatible with the basic assumptions and concepts of Minimalist Syntax. As regards its empirical adequacy, it was claimed that the NSA can account for the facts of obligatory coreferentiality between a reflexive and its antecedent as reflected in, for example, constructions where the reflexive forms the object complement of a verb. Attention was also given to constructions in which a pronoun either cannot or may (but need not) receive a reflexive interpretation. Since, in terms of the NSA, a coreferential relationship can only be established when the pronoun and an appropriate antecedent are merged together in a nominal shell headed by an identity focus light noun, it follows that sentences in which the pronoun cannot receive a reflexive interpretation will lack such a nominal shell. It was argued that the selection of an identity focus $n \mathrm{P}$ is determined by the lexical properties of verbs: an inherently reflexive verb selects an identity focus $n \mathrm{P}$ as its 
complement, whereas an inherently non-reflexive verb does not. In cases where the pronoun can be interpreted both reflexively and non-reflexively, but where neither interpretation can be established on purely grammatical grounds (that is, where the pronoun occurs without the identity focus marker-self, or the relevant verb is not inherently (non-)reflexive), it was argued that the option of interpreting the pronoun as reflexive/non-reflexive is determined by nonlinguistic information. A distinction was therefore made between grammatically reflexive sentences and pragmatically reflexive sentences, with only the former containing a nominal shell headed by an identity focus light noun.

Related to the fact that, in some contexts, Afrikaans allows a morphologically simplex pronoun to be interpreted both reflexively and non-reflexively, is the phenomenon that a pronoun can also occur without the suffix -self in certain obligatory reflexive constructions. This phenomenon is found where the sentence contains an inherently reflexive verb. It was claimed that this alternation between morphologically simplex and morphologically complex forms of the pronoun is related to the distinction between strong and weak pronouns (cf. Cardinaletti and Starke 1999). More specifically, it was posited that the complex -self forms in Afrikaans can only contain strong pronouns, which means that a form such as homself ("himself") is a spellout of a strong pronoun plus the identity focus $n$-head which forms the locus of - self. In other words, Afrikaans lacks a distinct form consisting of a weak pronoun plus -self. Speakers of Afrikaans thus seem to be using two forms when expressing obligatory reflexivity in structures containing an inherently reflexive verb: (i) the more conservative option of a weak pronoun without -self, and (ii) the more colloquial option of a strong pronoun plus -self.

As regards its conceptual adequacy, it was shown that the theoretical devices employed in the NSA are either provided by or compatible with the basic assumptions and concepts of Minimalist Syntax. In particular, unlike previous analyses, no special features are required for establishing a coreferential relationship between a reflexive and its antecedent. Rather, in terms of the NSA, such a relationship is established by means of $\varphi$-agreement in a probe-goal configuration, requiring no new mechanisms or features.

Although the focus was on the facts of Afrikaans, it seems plausible that the basic ideas employed in the NSA could profitably be extended to other languages as well, both those of the Germanic family and those belonging to typologically different families. Clearly, though, much comparative research is required in this regard, including research within the diachronic domain.

\section{References}

Abney, S. 1987. The English noun phrase in its sentential aspect. Doctoral dissertation. MIT.

Aboh, E. 2010. Information structuring begins with the Numeration. Iberia 2(1):12-42.

Baker, M. 1988. Incorporation. A theory of grammatical function changing. Chicago: University of Chicago Press. 
Baker, M. 2003. Agreement, dislocation, and partial configurationality. In A. Carnie, H. Harley and M.-A Willie (eds.) Formal approaches to function in grammar: In honor of Eloise Jelinek. Amsterdam: John Benjamins. pp. 107-132.

Benincà, P. and C. Poletto. 2004. Topic, focus and V2: Defining the CP sublayers. In L. Rizzi (ed.) The cartography of syntactic structures (Vol. 2). The structure of CP and IP. New York: Oxford University Press. pp. 52-75.

Bernstein, J. 2001. The DP hypothesis: Identifying clausal properties in the nominal domain. In M. Baltin and C. Collins (eds.) The handbook of contemporary syntactic theory. Oxford: Blackwell. pp. 536-561.

Biberauer, T. 2003. Verb second (V2) in Afrikaans: A minimalist investigation of word-order variation. Doctoral dissertation. University of Cambridge.

Biberauer, T. 2009. How "well-behaved" is Afrikaans? V2 in modern spoken Afrikaans. In H. Den Besten, F. Hinskens and J. Koch (eds.) Afrikaans. Ein Tryptichon. Amsterdam: Voortgang. pp. 76-208.

Biberauer, T., A. Holmberg and I. Roberts. 2008. Disharmonic word-order systems and the Final-over-Final-Constraint (FOFC). In A. Bisetto and F. Barbieri (eds.) Proceedings of XXXIII Incontro di Grammatica Generativa. Available online:

http://amsacta.cib.unibo.it/archive/00002397/01/PROCEEDINGS_IGG33.pdf (Accessed 25 May 2010).

Biberauer, T., A. Holmberg and I. Roberts. 2009. Linearization and the architecture of grammar: A view from the Final-over-Final Constraint. In V. Moscati and E. Servidio (eds.) StiL - Studies in Linguistics (Proceedings of XXXV Incontro di Grammatica Generativa) pp. 78-91.

Biberauer, T. and M. Richards. 2006. True optionality: When the grammar doesn't mind. In C. Boeckx (ed.) Minimalist essays. Amsterdam: John Benjamins. pp. 35-67.

Biberauer, T. and I. Roberts. 2005. Changing EPP-parameters in the history of English: Accounting for variation and change. English Language and Linguistics 9(1):5-46.

Biberauer, T. and I. Roberts. 2006. The loss of residual "head-final" orders and remnant fronting in Late Middle English. Causes and consequences. In J. Hartmann and L. Molnárfi (eds.) Comparative studies in Germanic Syntax. Amsterdam/Philadelphia: John Benjamins pp. 263-297.

Biberauer, T. and I. Roberts. 2010. Subjects, tense and verb-movement. In T. Biberauer, A. Holmberg, I. Roberts and M. Sheehan (eds.) Parametric variation: Null subjects in Minimalist Theory. Cambridge: Cambridge University Press. pp. 263-303.

Birner, B. and G. Ward. 1998. A semantico-pragmatic taxonomy of English inversion. Paper presented at the LSA Annual Meeting, 27-30 December 1989, Washington, D.C. 
Boeckx, C. and N. Hornstein. 2007. On non-obligatory control. In W.D. Davies and S. Dubinsky (eds.) New horizons in the analysis of control and raising in the series Studies in natural language and linguistic theory. Vol. 71: Dordrecht: Springer. pp. 251-262.

Boeckx, C., N. Hornstein and J. Nunes. 2010. Control as movement. Cambridge: Cambridge University Press.

Botha, M. and J. Oosthuizen. 2009. Die struktuur van die linker-sinsgrens in Afrikaans. Stellenbosch Papers in Linguistics Plus (SPIL PLUS) 37:1-68.

Büring, D. 2005. Binding theory. Cambridge: Cambridge University Press.

Cardinaletti, A. and M. Starke. 1999. The typology of structural deficiency: A case study of the three classes of pronouns. In H. van Riemsdijk (ed.) Clitics in the languages of Europe. Berlin: Mouton de Gruyter. pp. 145-233.

Chomsky, N. 1964. Current issues in linguistic theory. The Hague: Mouton.

Chomsky, N. 1981. Lectures on government and binding. Dordrecht: Foris.

Chomsky, N. 1982. Some concepts and consequences of the theory of government and binding. Cambridge, Mass.: MIT Press.

Chomsky, N. 1985. Knowledge of language: Its nature, origin and use. New York: Praeger.

Chomsky, N. 1986. Barriers. Cambridge, Mass.: MIT Press.

Chomsky, N. 1995. The minimalist program. Cambridge, Mass.: MIT Press.

Chomsky, N. 2000. Minimalist inquiries: The framework. In R. Martin, D. Michaels and J. Uriagereka (eds.) Step by step: Essays on minimalist syntax in honour of Howard Lasnik. Cambridge, Mass.: MIT Press. pp. 89-155.

Chomsky, N. 2001. Derivation by phase. In M. Kenstowicz. (ed.) Ken Hale. A life in language. Cambridge, Mass.: MIT Press. pp. 1-52.

Chomsky, N. 2004. Beyond explanatory adequacy. In A. Belletti (ed.) Structures and beyond. The cartography of syntactic structures (Vol. 3). Oxford: Oxford University Press. pp. 104-131.

Chomsky, N. 2005a. Three factors in language design. Linguistic Inquiry 36:1-22.

Chomsky, N. 2005b. On phases. Ms. published in R. Freidin, C. Otero and M. Zubizuretta (eds.) 2008. Foundational issues in linguistic theory. Cambridge, Mass.: MIT Press. pp. 133-166.

Chomsky, N. 2006. Approaching UG from below. Ms. published in U. Sauerland and H.-M. Gärtner (eds.) 2007. Interfaces and Recursion = Language? New York: Mouton de Gruyter. pp. 1-29. 
Chomsky, N. and H. Lasnik. 1993. The theory of principles and parameters. In N. Chomsky. (ed.) 1995. The minimalist program. Cambridge, Mass.: MIT Press. pp.

Cinque, G. 1993. A null theory of phrase and compound stress. Linguistic Inquiry 24(2):239297.

Cruschina, S. 2012. Focus in existential sentences. In V. Bianchi and C. Chesi (eds.) University of Manchester Internet Celebration for Luigi Rizzi's 60th Birthday. pp. 1-31. Available online: http://www.ciscl.unisi.it/gg60 (Accessed 10 September 2012).

Den Besten, H. 1977. On the interaction of root transformations and lexical deletive rules. In H. Den Besten. 1978. Cases of possible syntactic interference in the development of Afrikaans. Amsterdam Creole Studies II. University of Amsterdam. Publicaties van Het Instituut voor Algemene Taalwetenschap 20: pp. 5-56.

É. Kiss, K. 1998. Identification focus versus information focus. Language 74:245-273.

Erteschik-Shir, N. 2007. Information structure: The syntax-discourse interface. Oxford surveys in syntax and morphology. Oxford: Oxford University Press.

Fanselow, G. 2001. Features, $\theta$-roles, and free constituent order. Linguistic Inquiry 32(3):405437.

Folli, R. and H. Harley. 2004. Flavors of v: Consuming results in Italian and English. In R. Slabakova and P. Kempchinsky (eds.) Aspectual inquiries. Dordrecht: Kluwer. pp. 95-120.

Freidin, R. 1997. Review article: The minimalist program. Language 73(3):571-582. Giorgi, A. and G. Longobardi. 1991. The syntax of noun phrases. Cambridge: Cambridge University Press.

Gundel, J. 1999. On different kinds of focus. In P. Bosch and R. van der Sandt (eds.) Focus: Linguistic, cognitive and computational perspectives. Cambridge: Cambridge University Press. pp. 293-305.

Halle, M. and A. Marantz. 1993. Distributed morphology and the pieces of inflection. In K. Hale and S. Keyser (eds.) The view from Building 20: Essays in linguistics in honor of Sylvain Bromberge. Cambridge, Mass.: MIT Press. pp. 111-176.

Halpert, C. 2012. Argument licensing and agreement in Zulu. Doctoral dissertation. MIT.

Hartmann, J. 2008. Expletives in existentials: English there and German da. LOT Dissertation Series 181. Utrecht: LOT.

Heinat, F. 2005. Reflexives in a phase based syntax. Working Papers in Scandinavian Syntax 75:37-54. Department of Scandinavian Languages, Lund University.

Heinat, F. 2006a. Probes, pronouns, and binding in the minimalist program. Doctoral dissertation. Lund University. 
Heinat, F. 2006b. Probing phrases, pronouns, and binding. The Department of English in Lund: Working Papers in Linguistics 6:19-37.

Hicks, G. 2006. The derivation of anaphoric relations. Doctoral dissertation. University of York.

Holmberg, A. 1986. Word order and syntactic features in the Scandinavian languages and English. Doctoral dissertation. University of Stockholm.

Holmberg, A. 2000. Deriving OV order in Finnish. In P. Svenonius (ed.) The derivation of VO and $O V$. Oxford: Oxford University Press. pp. 123-152.

Hornstein, N. 1999. Movement and control. Linguistic Inquiry 30(1):69-96.

Hornstein, N. 2009. A theory of syntax. Minimal operations and universal grammar. Cambridge: Cambridge University Press.

Hornstein, N., J. Nunes and K. Grohmann. 2005. Understanding minimalism. Cambridge: Cambridge University Press.

Julien, M. 2002. Syntactic heads and word formation. Studies in Linguistics (Proceedings of XXXV Incontro di Grammatica Generativa). New York: Oxford University Press. pp. 78-91.

Kayne, R. 1994. The antisymmetry of syntax. Cambridge, Mass.: MIT Press.

Kayne, R. 2002. Pronouns and their antecedents. In S. Epstein and T. Seely (eds.) Derivation and explanation in the minimalist program. Oxford: Blackwell. pp. 133-166.

Keenan, E. 2009. Linguistic theory and the historical creation of English reflexives. In P. Crisma and G. Longobardi (eds.) Historical syntax and linguistic theory. Oxford: Oxford University Press. pp. 41-57.

Kenesei, I. 2005. Focus as identification. In V. Molnaar and S. Winkler (eds.) The architecture of focus. Berlin: Mouton. Available online:

http://www.nytud.hu/oszt/igazc/kenesei/publ/keneseifocusmay.pdf. (Accessed 22 September 2012).

Koopman, H. and D. Sportiche. 1991. The position of subjects. Lingua 85:211-258.

Kratzer, A. 1996. Severing the external argument from its verb. In J. Rooryck and L. Zaring (eds.) Phrase structure and the lexicon. Dordrecht: Kluwer. pp. 109-137.

Kuroda, S. 1988. Whether we agree or not: A comparative syntax of English and Japanese. Linguisticae Investigationes 12(1):1-47.

Lee-Schoenfeld, V. 2007. Beyond coherence: The syntax of opacity in German. Linguistics today Vol. 114. Amsterdam: John Benjamins. 
Longobardi, G. 1999. The structure of DPs: Some principles, parameters and problems. In M. Baltin and C. Collins (eds.) Handbook of contemporary syntactic theory. Oxford: Blackwell.

Manzini, M. and A. Rousseau. 2000. A minimalist theory of A-movement and control. Lingua 110(6):409-447.

Marantz, A. 1995. The minimalist program. In G. Webelhuth (ed.) Government and binding theory and the Minimalist Program. Oxford: Blackwell. pp. 349-382.

Marantz, A. 1997. No escape from syntax: Don't try morphological analysis in the privacy of your own lexicon. In A. Dimitriadis, L. Siegel, C. Surek-Clark and A. Williams (eds.) Penn Working Papers in Linguistics (Proceedings of the 21st Annual Penn Linguistics Colloquium) 4(2):201-225.

Myler, N. 2009. Form, function and explanantion at the syntax-morphology interface: Agreement, agglutination and post-syntactic operations. Extended version of Masters thesis. University of Cambridge.

Oosthuizen, J. 2013. Obligatory reflexivity in Afrikaans: A minimalist approach. Doctoral dissertation. University of Stellenbosch.

Ouali, A. 2008. On C-to-T Phi-feature transfer: The nature of agreement and anti-agreement in Berber. In R. D'Alessandro, G. Hrafnbjargarson and S. Fischer (eds.) Agreement restrictions. Berlin: Mouton de Gruyter. pp. 159-180.

Öztürk, B. 2008. Non-configurationality: Free word order and argument drop in Turkish. In T. Biberauer (ed.) The limits of syntactic variation. Amsterdam: John Benjamins. pp. 411-440.

Paoli, S. 2006. The fine structure of the left periphery: COMPs and subjects. Evidence from Romance. Lingua 117(6):1057-1079.

Pesetsky, D. and E. Torrego. 2004. Tense, case, and the nature of syntactic categories. In J. Guéron and J. Lecarme (eds.) The syntax of time. Cambridge, Mass.: MIT Press. pp. 495-537.

Pesetsky, D. and E. Torrego. 2007. The syntax of valuation and the interpretability of features. In S. Karimi, V. Samiian and W. Wilkins (eds.) Phrasal and clausal architecture: Syntactic derivation and interpretation. Amsterdam: John Benjamins. pp. 262-294.

Ponelis, F. 1979. Afrikaanse sintaksis. Pretoria: J.L. van Schaik.

Prince, E. 1988. The discourse functions of Yiddish expletive es + subject postposing. Papers in Pragmatics 2:176-194.

Reinhart, T. and E. Reuland. 1993. Reflexivity. Linguistic Inquiry 24(4):657-720.

Reuland, E. 2001. Primitives of binding. Linguistic Inquiry 32(3):439-492. 
Reuland, E. and M. Everaert. 2001. Deconstructing binding. In M. Baltin and C. Collins (eds.) The handbook of contemporary syntactic theory. Oxford: Blackwell. pp. 634-669.

Richards, M. 2007. On feature inheritance: An argument from the Phase Impenetrability Condition. Linguistic Inquiry 38(3):563-572.

Richards, M. 2011. Deriving the edge: What's in a phase? Syntax 14(1):74-95.

Rizzi, L. 1997. The fine structure of the left periphery. In L. Haegeman (ed.) Elements of grammar. Dordrecht: Kluwer. pp. 281-337.

Rizzi, L. 2007. On delimiting movement. Paper presented at the International Symposium of Cambridge-Connecticut- Hyderabad-Nanzan-Siena-Tsingua-Hua Consortium for Linguistics, 14-17 December 2007, Tsing-Hua, Taiwan.

Roberts, C. 1998. Focus, the flow of information, and universal grammar. In P. Culicover and L. McNally (eds.) The limits of syntax. San Diego: Academic Press. pp. 109-160.

Roberts, I. 2010. Agreement and head movement. Clitics, incorporation, and defective goals. Cambridge, Mass.: MIT Press.

Rochemont, M. 1986. Focus in generative grammar. Amsterdam: John Benjamins.

Rochemont, M. and P. Culicover. 1990. English focus constructions and the theory of Grammar. Cambridge: Cambridge University Press.

Smith, N. 1998. Does Chomsky exist? Glot International 3(1):9.

Smith, N. 1999. Chomsky: Ideas and ideals. Cambridge: Cambridge University Press.

Sperber, D. and D. Wilson. 1995. Relevance. Communication and cognition. Oxford: Blackwell.

Stowell, T. 1989. Subjects, specifiers, and X-bar theory. In M. Baltin and A. Kroch (eds.) Alternative conceptions of phrase structure. Chicago: University of Chicago Press. pp. 232262.

Vikner, S. 1995. Verb movement and expletive subjects in the Germanic languages. Oxford: Oxford University Press.

Ward, G. and B. Birner. 2001. Discourse and information structure. In D. Schiffrin, D. Tannen and H. Hamilton (eds.) The handbook of discourse analysis. Oxford: Blackwell. pp. 119-137.

Zeller, J. 2008. The subject marker in Bantu as an antifocus marker. Stellenbosch Papers in Linguistics (SPIL) 38:221-254.

Zwart, J.-W. 2002. Issues relating to a derivational theory of binding. In S. Epstein and T. Seely (eds.) Derivation and explanation in the minimalist program. Oxford: Blackwell. pp. 268-304. 